\title{
The Indian Summer Monsoon and its Sensitivity to the Mean SSTs: Simulations with the ECHAM4 AGCM at T106 Horizontal Resolution
}

\author{
Wilhelm MAY \\ Danish Meteorological Institute, Copenhagen, Denmark \\ (Manuscript received 29 March 2002, in revised form 10 October 2002)
}

\begin{abstract}
Seasonal mean features as well as subseasonal variations of the Indian summer monsoon are investigated on the basis of two simulations with the ECHAM4 atmospheric general circulation model at a high (T106) horizontal resolution. In the first one (period 1979-1993; AMI) observed monthly mean values of sea surface temperatures (SSTs) and sea-ice extent have been prescribed as lower boundary forcing to the model. The second one (period 1970-1999; TSL) is part of a time-slice experiment, where the atmospheric model has been forced by monthly mean values of SSTs, sea-ice extent and sea-ice thickness originating from a transient simulation with the ECHAM4/OPYC coupled atmosphere-ocean model at a low (T42) horizontal resolution. In TSL and the coupled simulation the concentrations of the important greenhouse gases have been prescribed according to observations until 1990, and after 1990 according to the IPCC scenario IS92a. In AMI the concentrations of the important greenhouse gases have been kept constant at a level close to the observed values for the period 1978-1988.

The comparison between AMI and observations indicates a quite realistic simulation of the seasonal mean characteristics of the Indian summer monsoon, as well as of its subseasonal variability, though some deficiencies remain. These are a warm bias of the seasonal mean temperature over land, leading to a too strong temperature difference between the Indian Ocean and the land areas to the north; an overestimation of the low-level monsoon flow, an underestimation of the upper-level monsoon flow; and, an underestimation of precipitation over India, in particular for the rainfall maximum near the west coast of the Indian peninsula. Other shortcomings are a northward shift and deformation of the ITCZ over the Indian Ocean and over the western Pacific. The latter is associated with an unrealistic simulation of the large-scale circulation over the western Pacific, including the East Asian monsoon. The underestimation of precipitation near the west coast of the Indian peninsula affects the patterns describing the day-to day-variability of rainfall during the monsoon season. Though the most prominent patterns of variability obtained from the simulations have structures similar to those obtained for observations, the strength of the center of action on the west coast of the Indian peninsula is considerably underestimated.

As for the seasonal mean features, most of the model deficiencies are improved in TSL. These improvements can be explained by the following mechanisms: (a) The initial warm temperature bias over the Indian Ocean acts to diminish the underestimation of precipitation over India, the warm temperature bias over India and Pakistan, and the too strong temperature difference between the Indian Ocean and the land areas to the north. (b) The El Niño-like warming pattern in the tropical Pacific helps to reverse the too strong low-level monsoon flow. (c) The erroneous SSTs in the western Pacific generated by the coupled model improve the simulation of the ITCZ and the large-scale circulation over the western Pacific, in particular the East Asian monsoon, and the ITCZ over the Indian Ocean via the Walker circulation. Little improvement is seen, however, in the simulation of the subseasonal variability.
\end{abstract}

Corresponding author: Wilhelm May, Lyngbyvej 100, 2100 Copenhagen, Denmark.

E-mail: may@dmi.dk

(C) 2003, Meteorological Society of Japan

\section{Introduction}

During the boreal summer season, the climate in Southeast Asia in general and in India 
in particular is dominated, respectively, by the Asian and Indian summer monsoon. The Asian summer monsoon returns with remarkable regularity every year and provides the rainfall for crops that sustain over $60 \%$ of the earth's population. It is not only a dominant feature of the general circulation in Southeast Asia but extends its influence to various remote regions. The arid regions in North Africa and the dry summers in the Mediterranean area may, for instance, be a direct consequence of the Asian summer monsoon (Rodwell and Hoskins 1996).

The monsoon circulation is mainly driven by the differential heating of the Indian Ocean and the adjacent land areas (e.g., Krishnamurti and Ramanathan 1982). Therefore, it is in part related to the Eurasian snow cover, as indicated in observational studies (e.g., Hahn and Shukla 1976; Dickson 1984; Sankar-Rao et al. 1996). Sensitivity experiments with atmospheric general circulation models (AGCMs) have shown that when spatially coherent excessive snow cover is imposed in Eurasia in spring, the monsoon circulation is relatively weak in the following summer (e.g., Douville and Royer 1996; Ferranti and Molteni 2000). There may also exist an inverse relationship between the Asian summer monsoon and the El Niño/Southern Oscillation (ENSO) phenomenon (e.g., Rasmusson and Carpenter 1983; Webster and Yang 1992). These observational studies have found that drought years over Southeast Asia (weak monsoon) are often related to warm sea surface temperature (SST) anomalies in the central and eastern tropical Pacific (El Niño) and wet years (strong monsoon) to anomalously cold SST-anomalies (La Niña). These relationships have also been identified in modelling studies (e.g., Ju and Slingo 1995; Lau and Nath 2000). But according to Krishna Kumar et al. (1999), the inverse relationship between ENSO and the Indian summer monsoon has weakened considerably in the last two decades. The strength of the Indian summer monsoon is also affected by the SSTs in the Indian Ocean. Joseph et al. (1994) reported, for instance, on a delay of the monsoon onset, generally indicating reduced precipitation during the monsoon season, in relation to warm SST anomalies at and south of the equator during the premonsoon season, i.e., March through May. In their modelling study Chandrasekar and Kitoh (1998) actually found a significant response over the entire Indian region to idealized SST anomalies placed in the Indian Ocean just south of the equator, namely a decrease in the monsoon precipitation and a weakening of the monsoon circulation.

During the established phase of the monsoon the circulation undergoes significant variations, usually referred to as "active/break cycles." These are manifested as fluctuations in the convection and the circulation, primarily associated with westward propagating events (1020 days, e.g., Krishnamurti and Bhalme 1976; Krishnamurti and Ardanuy 1980) and northward propagating events (30-60 days, e.g., Sikka and Gadgil 1980; Krishnamurti and Subramanian 1982; Gadgil and Asha 1992). The changes in the rainfall distribution in India, as well as other parts of Southeast Asia, between active and break cycles are substantial (e.g., Webster et al. 1998), so that the uneven spatial and temporal distribution of rainfall may have adverse effects, either as major floods or as major droughts. As for India, the rainfall has been found to be above normal in central India and below normal in both the northern (foothills of the Himalayas) and the southern parts of India during the active phase; the pattern is reversed during the break phase of the monsoon (Krishnamurthy and Shukla 2000). In the light of the pronounced changes between active and break cycles, the intraseasonal variability could have a significant impact on the seasonal mean rainfall. Krishnamurti and Bhalme (1976), Sikka and Gadgil (1980) or Gadgil and Asha (1992) have actually presented observational evidence that years with below-normal rainfall in central India are characterized by prolonged breaks in the Indian monsoon rainfall, while years with nearnormal or above-normal rainfall tend to have fewer breaks of shorter duration. However, Krishnamurthy and Shukla (2000) recently found that the nature of the intraseasonal variability is not different during the years of major droughts or major floods. Apparently, also a large-scale persistent seasonal mean component, possibly induced by variations of the snow cover, the soil moisture, or the SSTs, plays an important role for the monsoon rainfall. 
Since the Indian summer monsoon is a regional phenomenon, it is strongly affected by processes on spatial scales that are considerably smaller than the spatial scales typically resolved by atmospheric or coupled GCMs (e.g., Giorgi and Mearns 1991), which are on the order of 300 to $500 \mathrm{~km}$. Hence, these models cannot explicitly capture the fine-scale structures that characterize climate variables such as the near-surface temperature or precipitation for many parts of the globe. These models may have, therefore, difficulties in properly simulating the regional distributions of these variables, in particular when the orographic forcing, such as for India with the Western Ghats and the Himalayas, plays an important role. In order to improve the simulation of the regional phenomena, one can increase the horizontal resolution of the GCM considerably, to about $100 \mathrm{~km}$, so that smaller regional and temporal scales are explicitly resolved (e.g., Bengtsson et al. 1995; Martin 1999; Stratton 1999; May 2001). As for the simulation of the Asian summer monsoon, Martin (1999) found that in the case of the HadAM2B AGCM, the high horizontal resolution provides extra detail in the precipitation distribution, but the mean features of the monsoon are hardly altered and the systematic errors remain. Apparently the systematic errors in the monsoon simulation by HadAM2B are not a result of the coarse resolution, but may be related to problems with the physical parameterizations of the model. On the other hand, for the ECHAM3 and ECHAM4 AGCMs, Dümenil and Bauer (1998) observed a better simulation of the tropical easterly jet over South Asia, the Indian Ocean, and Africa at the high horizontal resolution. Further, the simulation of several aspects of the Indian summer monsoon, such as the distribution of precipitation in the vicinity of the Western Ghats, the structure of the cyclonic flow pattern over northeastern India or the strength of the low-level winds over the Bay of Bengal with ECHAM4, benefits considerably from the high horizontal resolution (Stendel and Roeckner 1998). In their study of the impact of the horizontal resolution (ranging from 200 to $600 \mathrm{~km}$ ) on the simulation of the Asian summer monsoon by ARPEGE-CLIMAT, Stephenson et al. (1998) found both an improvement and a deterioration of the quality of the simulation when the resolution is increased, because some of the model's systematic errors become accentuated at higher resolution.

In this study the simulation of various aspects of the Indian summer monsoon with the ECHAM4 AGCM at a horizontal resolution of T106, which corresponds to about $120 \mathrm{~km}$, is investigated. This includes aspects of the seasonal mean monsoon, as well as of subseasonal variations associated with active/break cycles of the monsoon. This is achieved by comparing a simulation with ECHAM4 for the period 1979-1993, where observed values of SSTs and sea-ice extent have been prescribed as lower boundary forcing, with atmospheric analyses and other observational data sets of precipitation for the corresponding period. This simulation is also compared to another simulation with ECHAM4 for the period 1970-1999, where the lower boundary forcing has been prescribed as obtained from a transient climate change simulation with a low-resolution coupled model (May and Roeckner 2001). By this, the impact of possible errors in the simulation of the SSTs in the tropical oceans in the coupled model on the simulation of the Indian summer monsoon can be assessed. In particular, this simulation with ECHAM4 is characterized by a general warm temperature bias due to the special experimental design of the transient climate change simulation (Roeckner et al. 1999). Therefore, the comparison between the two simulations with ECHAM4 also reveals the impact of this warm temperature bias on the simulation of the Indian summer monsoon.

The paper is organized as follows: In Section 2 the model experiments on which the study is based are described. Subsequently, the characteristics of the seasonal mean monsoon (Section 3 ) and of the monsoon's subseasonal variability (Section 4) are presented. A summary and the conclusions are given in Section 5 .

\section{Model experiments}

The model employed the ECHAM4 AGCM (Roeckner et al. 1996a). The model has been developed at the Max-Planck-Institute for Meteorology (MPI) for simulating the global present-day climate and a possible global change in climate due to enhanced emissions of greenhouse gases. It is based on the global forecasting system that is used at European Centre for 
Medium-Range Weather Forecasts (ECMWF), but several major changes have been made, in particular to the physical parameterizations, to make the model suitable for climate simulations.

In the simulations presented here, ECHAM4 has been run at a horizontal resolution of T106 (corresponding to $160 \times 320$ grid points on a Gaussian grid) and 19 vertical levels. In ECHAM4 most of the free parameters in the physical parameterizations are independent of resolution (note that they have been selected at a horizontal resolution of T42) instead of tuning the model by choosing an optimal set of parameters at the respective resolution. Only the parameterizations of a few processes, which have turned out to be extremely scale dependent, have been tuned individually at different horizontal resolutions, such as the parameterizations of gravity wave drag, horizontal diffusion, and formation of precipitation in stratiform clouds (Stendel and Roeckner 1998). Thus the high resolution does not automatically reduce all the systematic model errors, since some of the physical parameterizations, which have been tuned at the lower resolution, are possibly scale dependent. Nevertheless, the high resolution leads to a generally more realistic simulation of the present-day climate by ECHAM4, due to the inclusion of a much wider spectrum of spatial scales and, hence, the nonlinear interactions between them and a more realistic representation of the topography (Stendel and Roeckner 1998).

In the simulation covering the period December 1978 through February 1994 (referred to as "AMI," see Table 1) the lower boundary forcing has been derived from observed monthly mean values of SSTs and sea-ice extent.

Table 1.

\begin{tabular}{lcc}
\hline Data & Acronym & Period \\
\hline AMIP-type & AMI & December 1978- \\
experiment with & & February 1994 \\
ECHAM4 & & \\
Time-slice & TSL & January 1970- \\
experiment with & & December 1999 \\
ECHAM4 & & \\
ECMWF & ERA & December 1978- \\
re-analyses & & February 1994 \\
\hline
\end{tabular}

List of data (see Section 2).
For the period 1978-1988, the so-called "AMIPdataset" (Gates 1992), and for the subsequent years, data from NMC/CAC (Reynolds 1988) have been used. During this simulation the concentrations of the important greenhouse gases have been kept constant at a level close to the observed values during the period 19781988. In the other simulation for the period January 1970 through December 1999 (referred to as "TSL", see Table 1) the lower boundary forcing has been derived, however, from monthly mean values of SSTs, sea-ice extent, and sea-ice thickness from a transient climate change simulation performed with the ECHAM4/OPYC coupled climate model (Roeckner et al. 1996b). Moreover, the temporal evolution of the concentrations of the important greenhouse gases has been prescribed in the same way as in the climate change simulation (see below). This simulation under present-day climate conditions is part of a socalled "time-slice experiment," which also includes a simulation of the future climate (the period 2060-2089). Further details on the experimental design of the time-slice experiment are given in May (1999), and a thorough discussion of the changes in the mean climate inferred from these two time-slices can be found there, as well as in May and Roeckner (2001).

The climate change experiment has been performed at MPI with the ECHAM4/OPYC coupled atmosphere-ocean model. The coupled model consists of the ECHAM4 AGCM at a horizontal resolution of $\mathrm{T} 42$ and 19 vertical levels and an extension of the OPYC ocean model (Oberhuber 1993), including a sea-ice model. OPYC has 11 layers and a varying horizontal resolution: poleward of $36^{\circ}$ latitude the resolution is identical to that of the low resolution AGCM, about $2.8^{\circ}$. At low latitudes, the meridional grid spacing is gradually decreased to $0.5^{\circ}$ at the equator to allow for a better representation of the equatorial wave guide in the model and, hence, the ENSO phenomenon. The model components are coupled quasisynchronously and exchange information once daily. Annual mean flux-adjustments of heat and freshwater have been estimated from a 100-year spinup of the coupled model. Further details on the coupling technique and the performance of the model can be found in Roeckner et al. (1996b) and Bacher et al. (1998). 
The coupled model has been used for a control experiment (Roeckner et al. 1996b) and for three different time-dependent forcing experiments, which are thoroughly described in Roeckner et al. (1999). In the climate change simulation used here (referred to as "GHG" in Roeckner et al. 1999) the concentrations of various gases have been prescribed as a function of time: the greenhouse gases $\mathrm{CO}_{2}, \mathrm{CH}_{4}, \mathrm{~N}_{2} \mathrm{O}$ and several industrial gases such as chlorofluorocarbons (CFC-11, 12, 113, 114, 115), hydrochlorofluorocarbons (HCFC-22, 123, 141b), hydrofluorocarbons (HFC-125, 134a, 152a), carbon tetrachloride $\left(\mathrm{CCl}_{4}\right)$ and methylchloroform $\left(\mathrm{CH}_{3} \mathrm{CCl}_{3}\right)$. From 1860 to 1990 the annual mean concentrations of these gases have been prescribed as observed and after 1990 according to the Intergovernmental Panel on Climate Change (IPCC) scenario IS92a (Houghton et al. 1992). For the industrial gases, the IS92ascenario has been updated to be consistent with a "Copenhagen-like" emission scenario (Houghton et al. 1996). Ozone and aerosols, on the other hand, have been prescribed in the same way as in the control run, that is, as climatological distributions for the present-day conditions. Because present-day observations were employed for the spin-up of the ocean and for deriving the flux adjustment (Bacher et al. 1998), the initial state in the climate change simulation corresponds to modern, rather than pre-industrial time. Furthermore, the concentrations of $\mathrm{CO}_{2}, \mathrm{CH}_{4}$ and $\mathrm{N}_{2} \mathrm{O}$ for the year 1990 are used, rather than the pre-industrial ones, so that this initial shift of the concentrations had to be taken into account by enhancing the observed/projected concentrations of these gases in an appropriate way (see Roeckner et al. (1999) for details). Although this approach allows for a reasonably correct computation of the radiative forcing, it does not account for the warm bias of the initial state. But since the initial warm temperature bias is maintained throughout the simulation, it has no influence on the simulated climatic changes.

As a representation of the real atmosphere, ECMWF re-analyses (referred to as "ERA," see Table 1) for the period December 1978 through February 1994 (Gibson et al. 1997) are used. For precipitation, the 24-hour forecasts have been chosen instead of the respective analyses in order to avoid the spinup, which causes an underestimation of precipitation by about $15 \%$ in the analyses (Stendel and Arpe 1997). But since the analysis of precipitation may be affected by the characteristics of the model used for the re-analyses, other observational data sets of precipitation are considered as well. For instance, ERA is characterized by excessive precipitation in the tropics (Stendel and Arpe 1997). Annamalai et al. (1999) investigated the quality of ERA with regard to the simulation of the Asian summer monsoon and found that ERA is superior to the NCEP/NCAR reanalyses in several respects. In particular, the overall better simulation of precipitation and, hence, of the diabatic heating fields over the monsoon domain in ERA means that the analysed circulation is probably closer to reality. The ECMWF re-analyses are also very suitable for the purposes of this study, since they have the same (high) horizontal resolution as the simulations with ECHAM4 (T106). Both the model data and the analyses have been available twice daily (00 and 12 UTC).

\section{Seasonal mean characteristics}

This section investigates the simulation of various aspects of the seasonal mean (June to September) Indian summer monsoon. These include the near-surface temperature, the large-scale circulation, and precipitation in the area comprising the Indian Ocean, Southeast Asia and the western Pacific, that is, the area $\left(20^{\circ} \mathrm{S}-40^{\circ} \mathrm{N}, 30-150^{\circ} \mathrm{E}\right)$.

\subsection{Near-surface temperature}

Figure 1 shows (a) the long term seasonal mean values of the near-surface temperature for the simulation with the observed values of SSTs and sea-ice extent as lower boundary forcing (AMI) and the differences between the various data sets: (b) the difference between AMI and the ECMWF re-analyses (ERA), (c) the difference between the time-slice experiment (TSL) and AMI, and (d) the difference between TSL and ERA (see Section 2). As for the differences, the shading indicates the statistical significance according to a two-sided $t$-test. Positive (negative) significant differences at the 97.5\%-level for the differences with ERA and at the 95\%-level for the differences between the two simulations, respectively, are marked by the dark (light) grey shading. 
Temperature in $2 \mathrm{~m}$
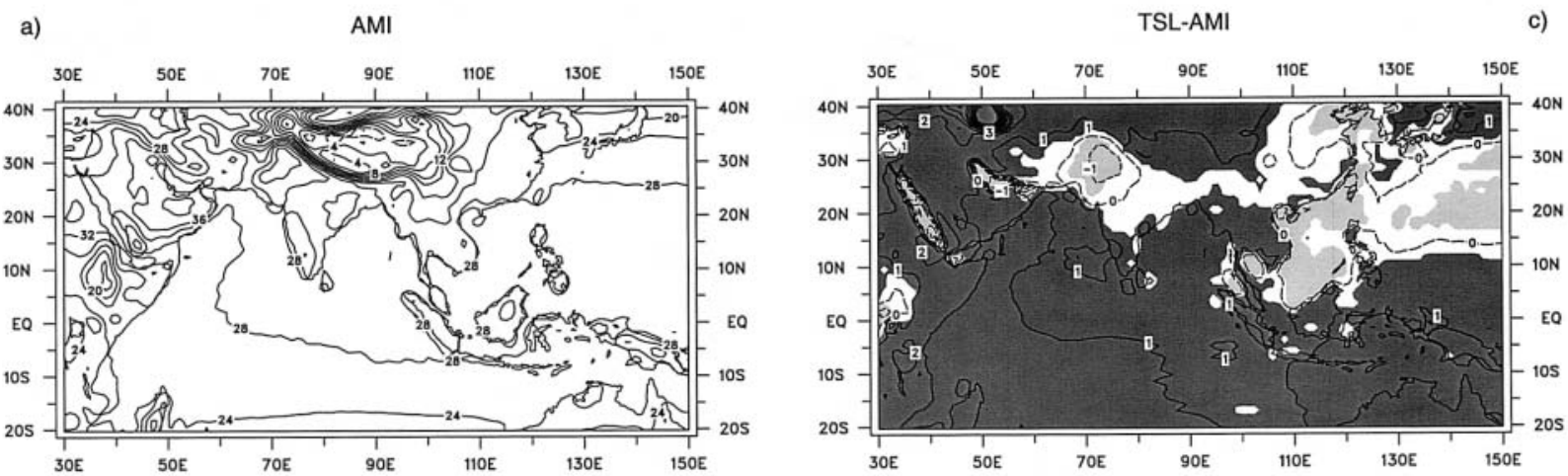

b)

AMI-ERA
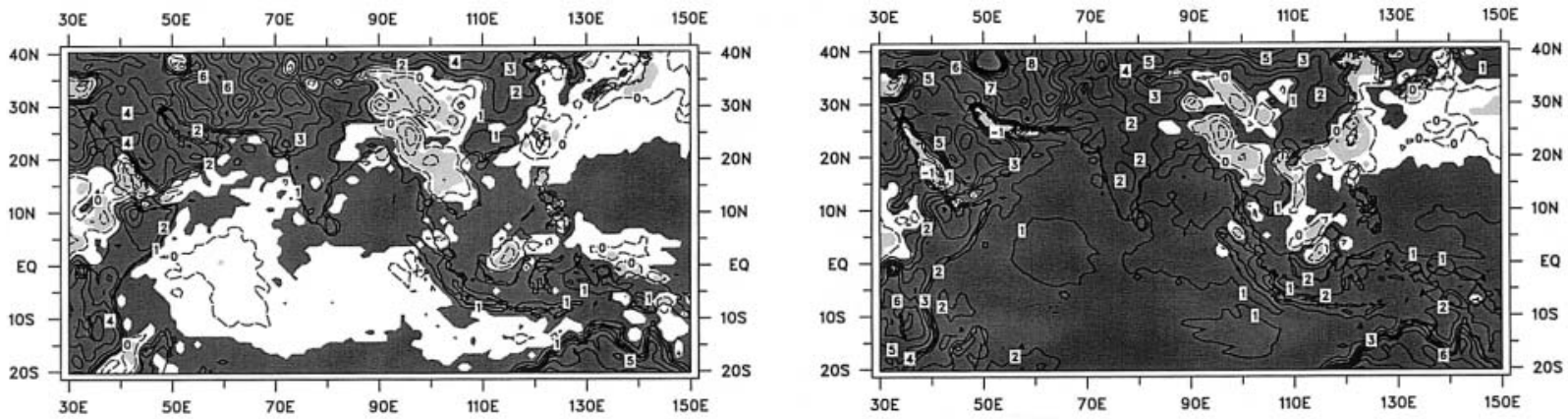

Fig. 1. Seasonal mean (June, July, August and September) of the temperature in $2 \mathrm{~m}$ for (a) the simulation with the observed values of SSTs and sea-ice extent as lower boundary forcing (AMI), as well as (b) the difference between AMI and the ECMWF re-analyses (ERA), (c) the difference between the simulation from the time-slice experiment (TSL) and AMI, and (d) the difference between TSL and ERA. The shading indicates the statistical significance of the differences at the 97.5\%-level for the differences with ERA $(b, d)$ and at the 95\%-level for the differences between the two simulations (c), respectively. Positive significant differences are marked by the dark, negative ones by the light grey shading. Units are $\left[{ }^{\circ} \mathrm{C}\right]$. The contour interval is $2^{\circ} \mathrm{C}$ (a) and $1^{\circ} \mathrm{C}(\mathrm{b}-\mathrm{d})$, respectively.

According to this, the model simulates a wide range of near-surface temperatures in the area of interest (Pakistan, India, Bangladesh, and the eastern regions of Southeast Asia), ranging from more than $36^{\circ} \mathrm{C}$ in Pakistan to less than $0^{\circ} \mathrm{C}$ in the highest parts of the Himalayas (Fig. 1a). As compared to ERA, AMI is characterized by a warm temperature bias of up to several degrees for most of the land areas (Fig. 1b). The largest deviations, exceeding $5^{\circ} \mathrm{C}$, occur in the interior of the continents in the subtropical areas of both the Northern and Southern Hemisphere. The warm temperature bias over land is related to an unrealistic drying of the ground during the dry season (boreal winter and spring), leading to a reduction of evaporation and, hence, of the local production of precipitation during the wet season. The physical parameterizations involved are the parameterization of the soil processes and the parameterization of the vertical fluxes in the planetary boundary layer. Since the ground's capacity for storing water is rather limited (Dümenil and Todini 1992), ECHAM4 does not only store too little water during the wet season (summer and autumn) but also evaporates too much water in the dry season. Too strong vertical moisture fluxes in the planetary boundary layer may further accelerate the drying. The annual cycle of precipitation in India and Bangladesh as si- 
mulated in AMI indeed reflects these deficiencies, as it is characterized by excessive precipitation in the period March through May and not enough precipitation between June and August (not shown here). As for the region of interest, the warm temperature bias is found in Pakistan and over the Indian subcontinent, but further to the east the simulation is characterized by a cold temperature bias, presumably related to the model's differences in the orography with higher elevations in this area with the Shan mountains in China and the complex terrain with various mountain ranges in Burma, Thailand, and Indochina.

Consistent with the initial warm temperature bias of the time-slice experiment due to the special experimental design of this simulation (see Section 2), the near-surface temperatures in TSL exceed those for AMI by about $1^{\circ} \mathrm{C}$ in various regions (Fig. 1c). The only areas with significant negative differences with a physical cause between the two simulations are found over Pakistan, the South China Sea, and the western Pacific Ocean between 15 and $30^{\circ} \mathrm{N}$. The negative differences in small ocean basins such as the Red Sea, the Persian Gulf, or the Yellow Sea to the west of Korea are due, on the other hand, to erroneous SSTs in these areas in TSL. These, in turn, are caused by the mismatch of the land-sea masks in the highresolution version of the ECHAM4 AGCM and the low-resolution coupled model that has provided the lower boundary forcing (May 1999). The lower temperatures in Pakistan are due to excessive precipitation in TSL in this region (see Fig. 5c), while the lower temperatures over the Pacific and the South China Sea are related to the fact that the SSTs as simulated by the coupled model in these areas are slightly too cold in boreal summer (Bacher et al. 1998). As a consequence, the near-surface temperatures simulated in TSL are generally warmer than in ERA (Fig. 1d). The temperature bias is smaller, however, than in AMI in several regions, such as in Pakistan, Burma, and Indochina, as well as over the western Pacific Ocean.

The aforementioned deviations between the different data sets have an effect on the temperature difference between the Indian Ocean and the land areas to the north and, therefore, may alter the simulation of the Indian summer monsoon (e.g., Krishnamurti and Ramanathan
1982). Both simulations are characterized by a too strong temperature difference compared to ERA, due to a considerable warm temperature bias over most of the land areas, in particular on the Arabic peninsula, as well as in Pakistan and India. This suggests both that the onset of the Indian summer monsoon occurs too early and that the monsoon circulation is too strong in the simulations. The deviation from ERA is somewhat smaller (about $1-2^{\circ} \mathrm{C}$ ) in TSL than for AMI (Fig. 1c), so that the possible impact of the too-strong temperature difference is less severe in the time-slice experiment. The positive temperature bias over the western tropical Pacific is accompanied by a negative temperature bias in the eastern tropical Pacific in AMI as well as for TSL (not shown), possibly leading to a too-strong monsoon flow in the simulations (e.g., Ju and Slingo 1995). As for TSL, negative temperature deviations also occur over the South China Sea and Indonesia (Fig. 1d). The positive temperature bias over the Indian Ocean, however, is generally associated with a weak Indian summer monsoon (Chandrasekar and Kitoh 1998). The opposite effect, i.e., a relatively strong Indian summer monsoon, has the reduction of the depth and the extent of the Eurasian snow cover in spring in TSL, due to the too-warm temperatures in this region (e.g., Douville and Royer 1996).

\subsection{Large-scale circulation}

During the established phase of the Indian summer monsoon, the large-scale flow in the lower troposphere, i.e., at $850 \mathrm{hPa}$, as simulated in AMI, is characterized by a crossequatorial flow near the African coast, forming the so-called "Somali-jet," and a westerly flow over the Arabian Sea, India, and the eastern parts of Southeast Asia, respectively (Fig. 2a). Over the Bay of Bengal, AMI reveals the characteristic cyclonic flow pattern with a southerly flow from the Bay of Bengal into Bangladesh and northeast India. On the other hand, in the upper troposphere, i.e., at $200 \mathrm{hPa}$, the simulated large-scale flow during the monsoon season is dominated by a northward shift of the subtropical westerly jet and a band of easterly winds over the northern and tropical Indian Ocean, also referred to as the "tropical easterly jet" (Fig. 2b). An extended anticyclone is located over the southern part of the Arabian 
AMI-ERA

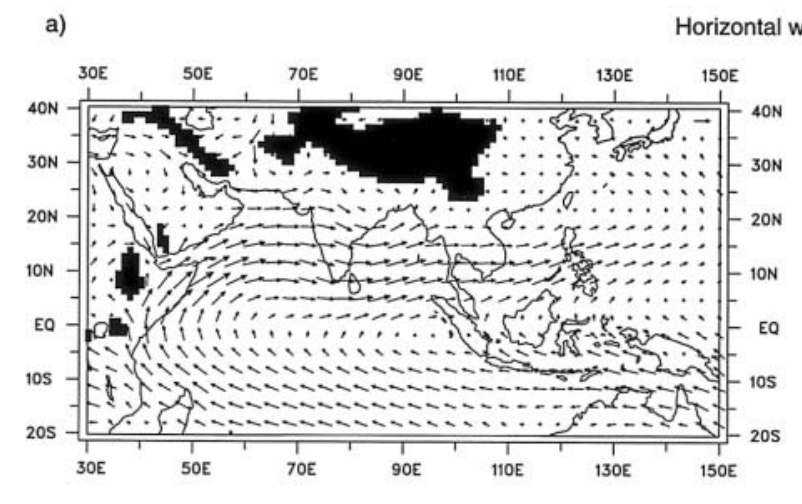

orizontal wind at $850 \mathrm{hPa}$

c)

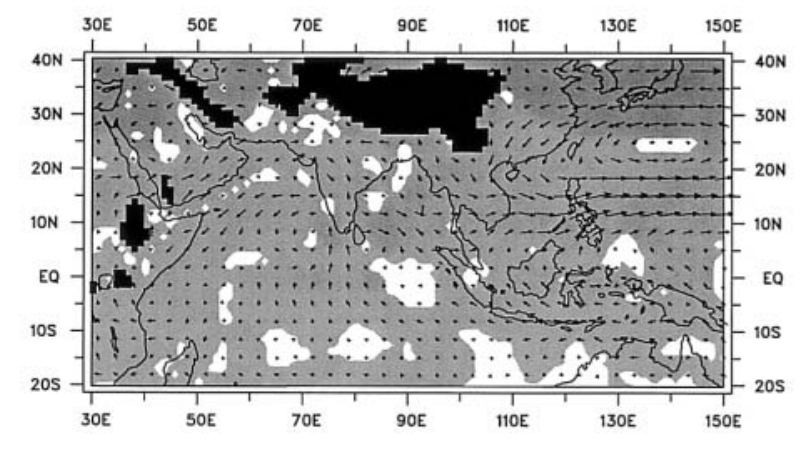

b)

Horizontal wind at $200 \mathrm{hPa}$

d)
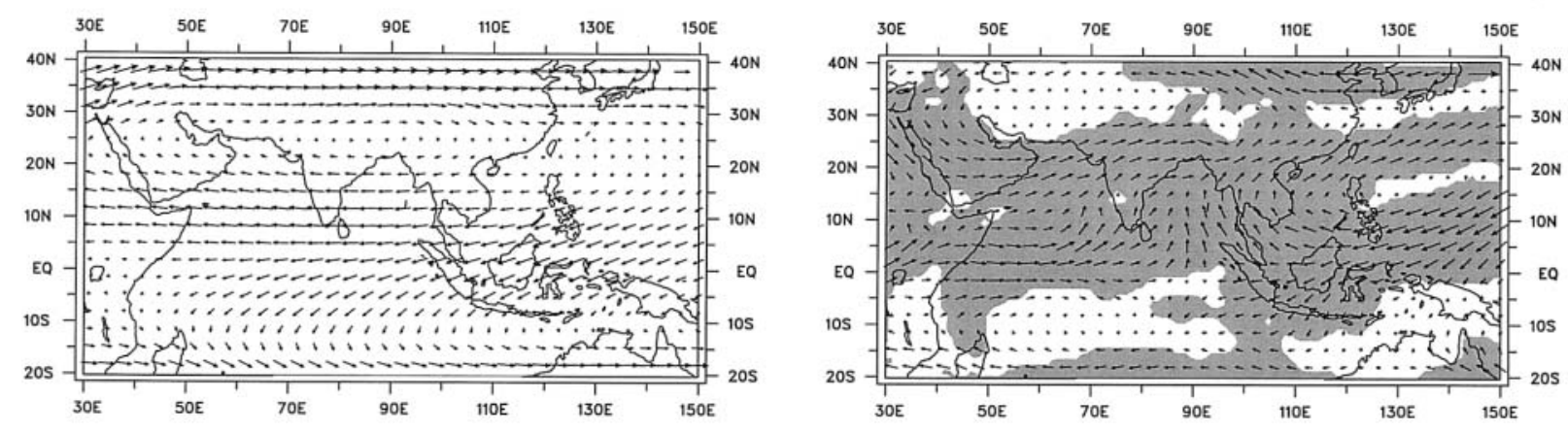

Fig. 2. Seasonal mean values of (a) the horizontal wind at $850 \mathrm{hPa}$ and (b) the horizontal wind at $200 \mathrm{hPa}$ for AMI, as well as the difference between AMI and ERA for (c) the horizontal wind at $850 \mathrm{hPa}$ and $(\mathrm{d})$ the horizontal wind at 200. The shading indicates the statistical significance of the differences at the $97.5 \%$-level. Units are $[\mathrm{m} / \mathrm{s}]$. The arrows in the upper right corner represent $8 \mathrm{~m} / \mathrm{s}$ (a, c and d) and $16 \mathrm{~m} / \mathrm{s}$ (b), respectively. Terrain higher than $1500 \mathrm{~m}$ is blanked out (a, c).

Peninsula, Pakistan, northern India, and the northeastern part of Southeast Asia. As a consequence of the westerly winds in the lower troposphere and the easterly winds in the upper troposphere, there is a positive vertical wind shear in the tropics and the Northern Hemisphere subtropics centred over the Indian Ocean.

Apparently, the model quite realistically simulates the general structure of the largescale flow in the region affected by the Indian summer monsoon. As for the low-level flow, only relatively small deviations from ERA can be found in the respective region (Fig. 2c). These are a slight underestimation of the westerly winds over the southern part of the Arabian Sea and a small overestimation over the Arabian Peninsula and the northern part of the Arabian Sea, indicating a northward shift of the band with westerly winds. Also over the Indian subcontinent the winds are relatively strong in AMI. Over the Bay of Bengal, the southerly flow component is too weak, while the westerly component is too strong. As a consequence, AMI is characterized by a too strong westerly flow over Burma and Indochina, the South China Sea, and further downstream over the western Pacific. The western Pacific is actually the area where rather large deviations from ERA can be found, namely, westerly wind anomalies in the zone between about 7 and $23^{\circ} \mathrm{N}$ and easterly ones to the north of about $27^{\circ} \mathrm{N}$. These deviations are related to a northeastward shift of the simulated high-pressure system centred over the subtropical and extratropical Pacific relative to ERA (not shown). 
As a consequence, the southerly flow over the South China Sea into China, the so-called "East Asian monsoon" is not captured in AMI.

As for the upper-level flow, several deviations from ERA can be found (Fig. 2d). Over the northern Indian Ocean, as well as over the Arabian Peninsula and northern India the easterly winds are underestimated in AMI, as illustrated by the westerly wind anomalies in these areas. Further, the northerly wind anomalies over the Arabian Peninsula and the southerly ones over Southeast Asia indicate too-weak southerly winds on the western side of the anticyclone and too-weak northerly winds on its eastern side. Apparently, the model underestimates the upper-level anticyclonic circulation over the land areas north of the Indian Ocean. Another area with marked deviations from ERA includes Borneo, the South China Sea, and the western part of the Pacific Ocean. Those are easterly wind anomalies between the equator and about $15^{\circ} \mathrm{N}$, westerly ones north of about $20^{\circ} \mathrm{N}$, and southerly deviations over the South China Sea. Apparently, both the easterly winds in the zone between the equator and $15^{\circ} \mathrm{N}$ and the westerly winds between 20 and $30^{\circ} \mathrm{N}$ are considerably enhanced in AMI. These deviations are related to the aforementioned deficiencies in simulating the atmospheric pressure over the western Pacific and are dynamically consistent with the respective deviations of the low-level flow, which are located about $5^{\circ}$ further to the north and point into the opposite direction (see Fig. 2c).

Compared to ERA, the positive vertical wind shear in the tropics and the Northern Hemisphere subtropics, as simulated in AMI, is too small over the western Indian Ocean and too large over the eastern part of Southeast Asia and the western Pacific. In the eastern part of the area this reflects both an overestimation of the westerly winds in the lower troposphere and of the easterly winds in the upper troposphere, by the model while in the western part the differences are mainly associated with an underestimation of the easterly upper-level winds (see Figs. 2c, d). The negative differences over northern India and the extratropical western Pacific, on the other hand, are related to an underestimation of the easterly winds on the northern side of the tropical easterly jet, as well as to an overestimation of the lower-level easterly winds over northern India and the extratropical Pacific.

As for the low-level flow, one of the main differences between the two simulations (Fig. 3a) are the easterly wind anomalies over the Bay of Bengal, Indochina, and the South China Sea, indicating relatively weak westerly winds in these areas in TSL. Also over the Indian subcontinent TSL is characterized by relatively weak winds, indicating a reduction of the lowlevel monsoon flow in TSL compared to AMI. Over the western Pacific, the distribution is characterized by easterly wind anomalies in the zone between about 7 and $23^{\circ} \mathrm{N}$ and westerly ones to the north of about $27^{\circ} \mathrm{N}$. Hence, compared to the respective differences between AMI and ERA (see Fig. 2c), they point into the opposite direction, indicating a much more realistic simulation of the low-level flow in this region in TSL. Also, in the upper troposphere the differences between TSL and AMI over the western tropical Pacific (Fig. 3b) point in the opposite direction of the deviations between AMI and TSL (see Fig. 2d). Another marked difference between the two simulations are the southwesterly wind anomalies extending from the southeastern Indian Ocean over Indonesia into the area over the western tropical Pacific, illustrating a reduction of the upper-level crossequatorial northeasterly flow from the Pacific into the Indian Ocean basin (see Fig. 2b) in TSL. The differences between the two simulations can be explained by the El Niño-like warming pattern in the tropical Pacific that is one of the main features of the climate change experiment (Roeckner et al. 1999). According to Ju and Slingo (1995) as well as other studies, El Niño events are typically associated with a relatively weak Indian summer monsoon.

As a consequence of the aforementioned differences between the two simulations, the biases of the low-level flow are generally smaller in TSL (Fig. 3c) than for AMI (see Fig. 2c). The relatively strong westerly winds over southern India, the Bay of Bengal, Burma, and Indochina cannot be found, illustrating a more realistic simulation of the low-level monsoon flow in TSL. Further, the strength of the anomalous cyclonic flow pattern over the western Pacific is reduced by about $60 \%$ compared to AMI. Related to this, the East Asian mon- 
TSL-AMI

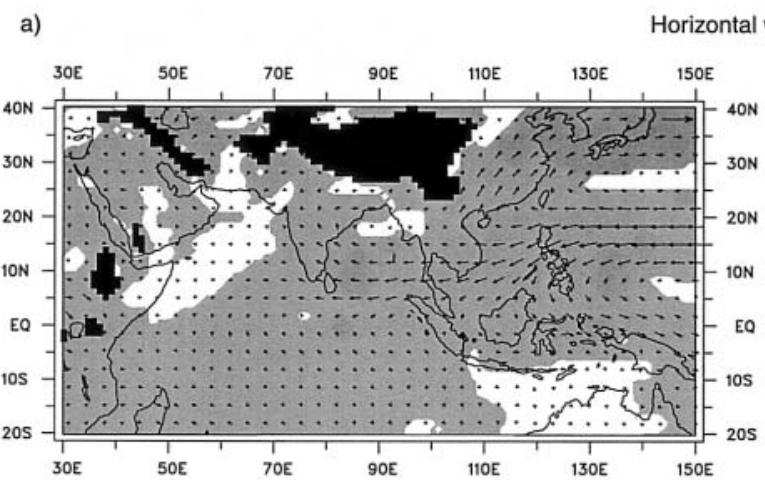

TSL-ERA

c)

b)

Horizontal wind at $200 \mathrm{hPa}$

d)
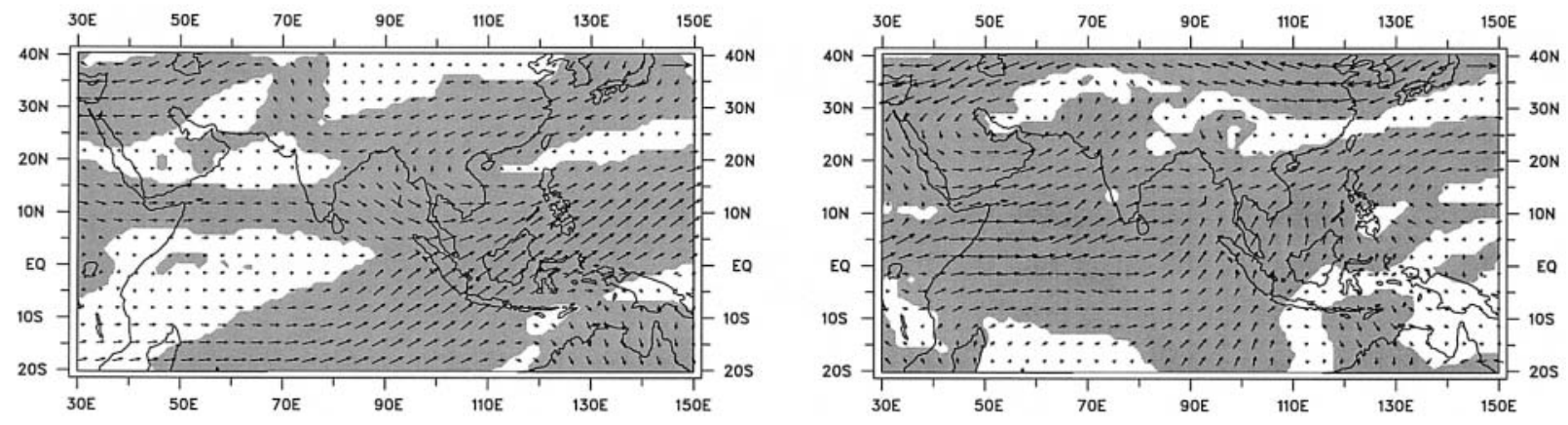

Fig. 3. Difference between TSL and AMI for (a) the horizontal wind at $850 \mathrm{hPa}$ and (b) the horizontal wind at $200 \mathrm{hPa}$, as well as (c, d) the respective differences between TSL and ERA. The shading indicates the statistical significance of the differences at the 97.5\%-level for the differences with ERA (c, d) and at the 95\%-level for the differences between the two simulations (a, b), respectively. The arrows in the upper right corner represent $8 \mathrm{~m} / \mathrm{s}$. Terrain higher than $1500 \mathrm{~m}$ is blanked out (a, c).

soon is also simulated quite realistically in TSL. Apparently, in TSL the atmospheric pressure over the western Pacific as well as the location of the high-pressure system over the $\mathrm{Pa}$ cific, is simulated more realistically, although the SSTs in this area deviate from the observed state (see Fig. 1d). The negative temperature bias in the western subtropical Pacific is associated with less precipitation (see Fig. 5c) and, hence, reduced latent heat release in this region. This, in turn, leads to an increase of the atmospheric pressure over the western subtropical Pacific (not shown). Also, in the upper troposphere the bias over the western Pacific is markedly smaller in TSL (Fig. 3d) than in AMI (see Fig. 2d). But in TSL, the westerly wind anomalies over much of the Indian Ocean basin illustrate a deterioration of the simulation of the upper-level flow in this region.

\subsection{Precipitation}

The most important aspect of the Indian summer monsoon is the rainfall occurring in the monsoon season. But since the analysis of precipitation in ERA may be affected by the characteristics of the model used to produce the analyses, other observational data sets of precipitation are considered as well. ERA, for instance, is characterized by excessive precipitation in the tropics (Stendel and Arpe 1997). Such data sets either originate from rain gauge observations, or are derived from remote sensing devices. Here, for instance, monthly-mean rain gauge data assembled by the Global Pre- 
Precipitation
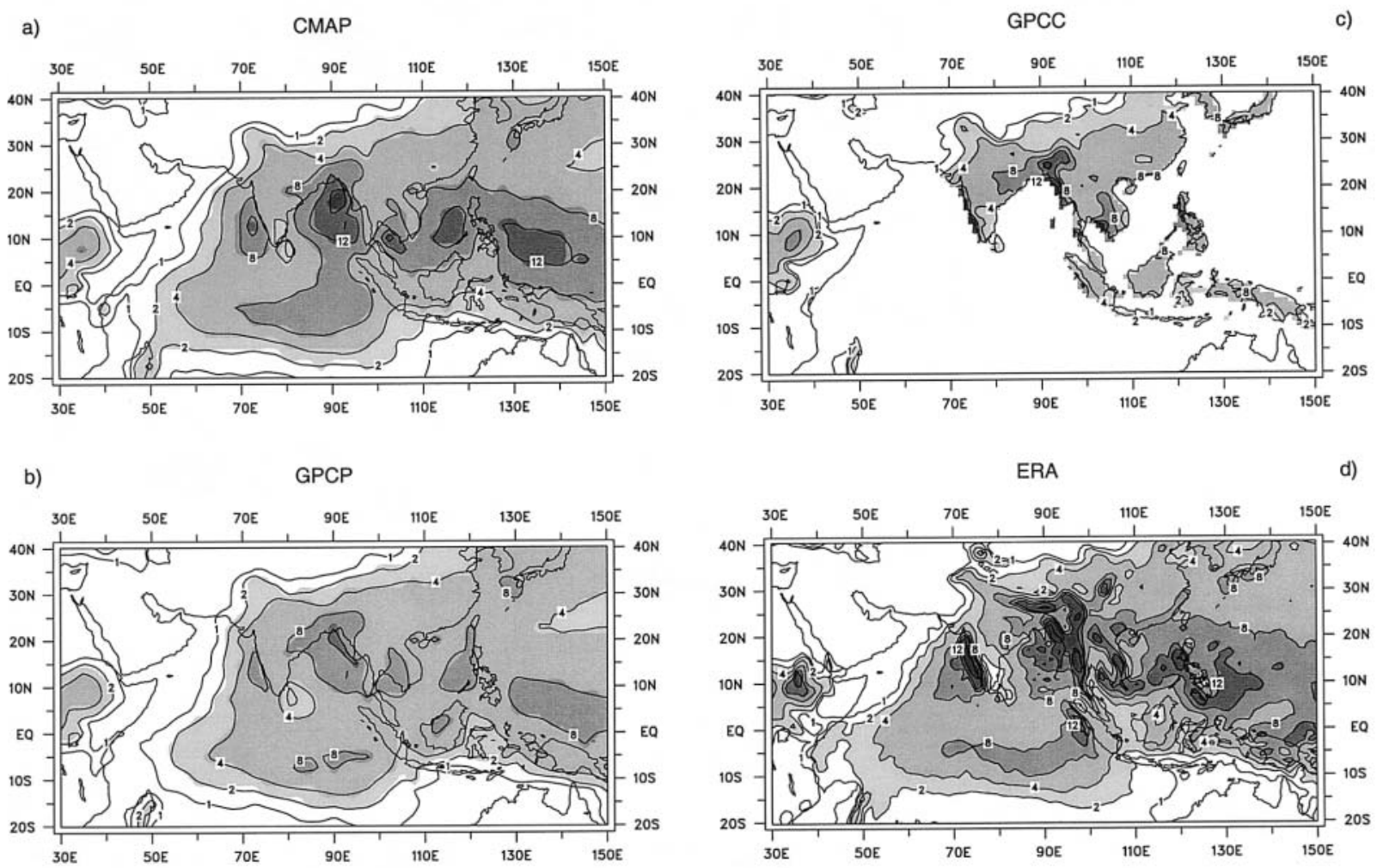

Fig. 4. Seasonal mean (June, July, August and September) of daily precipitation for the period 1979-1993 for different data sets, that are (a) CMAP, (b) GPCP, (c) GPCC (period 1986-1993, though), and (d) ERA (see text for further details). Units are [mm/d]. The contour lines shown are at $1,2,4,8,12,16$ and $24 \mathrm{~mm} / \mathrm{d}$, and the different shades of grey indicate the intensity of daily rainfall. In (c) contour lines are only drawn on the land areas.

cipitation Climatology Centre (GPCC) at a resolution of $1.0^{\circ}$ for the period 1986-2001 (Rudolph 1993) are used. Also considered are monthly mean rainfall data from the Climate Prediction Center Merged Analysis of Precipitation (CMAP) prepared by Xie and Arkin (1996) and from the Global Precipitation Climatology Project (GPCP) Version 2 data sets. These have a resolution of $2.5^{\circ}$ and cover the periods 1979-1999 (CMAP) and 1979-2001 (GPCP), respectively. The GPCP Version 2 data set is an extension of the GPCP Version 1 data set (Huffman et al. 1995) and includes among others precipitation estimates from TOVS (Susskind et al. 1997). Daily rainfall data from the GPCP data set for the period 1997-2001 at a fine resolution of $1.0^{\circ}$ are considered as well.

Figure 4 shows the long-term seasonal mean values of daily precipitation obtained from dif- ferent observational data sets and ERA. Apparently precipitation is overestimated in ERA (Fig. 4d) in various areas, in particular compared to the combined data sets at coarse resolution (Figs. 4a, b). The comparison between these two data sets actually reveals that over the oceans precipitation is markedly stronger in CMAP (Fig. 4a), whereas over land it is somewhat higher in GPCP (Fig. 4b). In some subtropical areas such as over the Arabian Sea, the Bay of Bengal, or the South China Sea CMAP exceeds GPCP by $50 \%$ or more. The comparison with GPCC (Fig. 4c) suggests that CMAP is a better representation of reality than GPCP. First, in various regions GPCC gives less precipitation than GPCP and, hence, is closer to CMAP. Furthermore, in various coastal regions, such as on the west coast of the Indian peninsula, in Burma, or in Bangladesh, 
GPCC gives markedly more precipitation than GPCP. The comparison of ERA with CMAP or GPCC reveals a general overestimation of rainfall in ERA in the regions on the mountainous west coasts of the continental landmasses and of the major islands, such as the Indian peninsula, Sumatra, or the Phillipines. Further, ERA is characterized by too much precipitation in association with orographic forcing in the Himalayan foothills as well as in Laos and Vietnam.

According to Fig. 5a, the model can simulate quite well many aspects of the typical distribution of rainfall associated with the monsoon. These include the characteristic maxima on the west coast of the Indian peninsula, over the Bay of Bengal, and in Bangladesh and northeastern India. In the western and southern parts of the Indian peninsula, on the other hand, precipitation is relatively weak. However, the model has a deficiency in realistically simulating the rainfall associated with the intertropical convergence zone (ITCZ) over the Indian Ocean with too much precipitation in the area southwest of India just north of the equator. This discrepancy is the only marked difference between AMI and ERA with regard to the geographical distribution of precipitation over the Indian Ocean and the adjacent land areas, but precipitation is generally weaker than in ERA. However, as precipitation is generally overestimated in ERA, in the area of interest the simulation actually is in better agreement with observations than ERA. In particular, the model does not simulate the excessive rainfall in association with orographic forcing, such as in the Himalayan foothills. The comparison with both CMAP (see Fig. 4a) and GPCC (see Fig. 4c) reveals that in AMI precipitation is considerably underestimated near the west coast of the Indian peninsula, i.e., by about 50\%. Further, AMI does not give enough precipitation over the western part of the Bay of Bengal. Another deficiency of AMI is the excessive rainfall over the South China Sea and the western Pacific in the zone between 10 and $20^{\circ} \mathrm{N}$. The excessive rainfall east of the Philippines indicates that in AMI the location of the ITCZ over the western Pacific is located about $10^{\circ}$ too far to the north.

One of the most important differences between TSL (Fig. 5b) and AMI is that the erro-
Precipitation
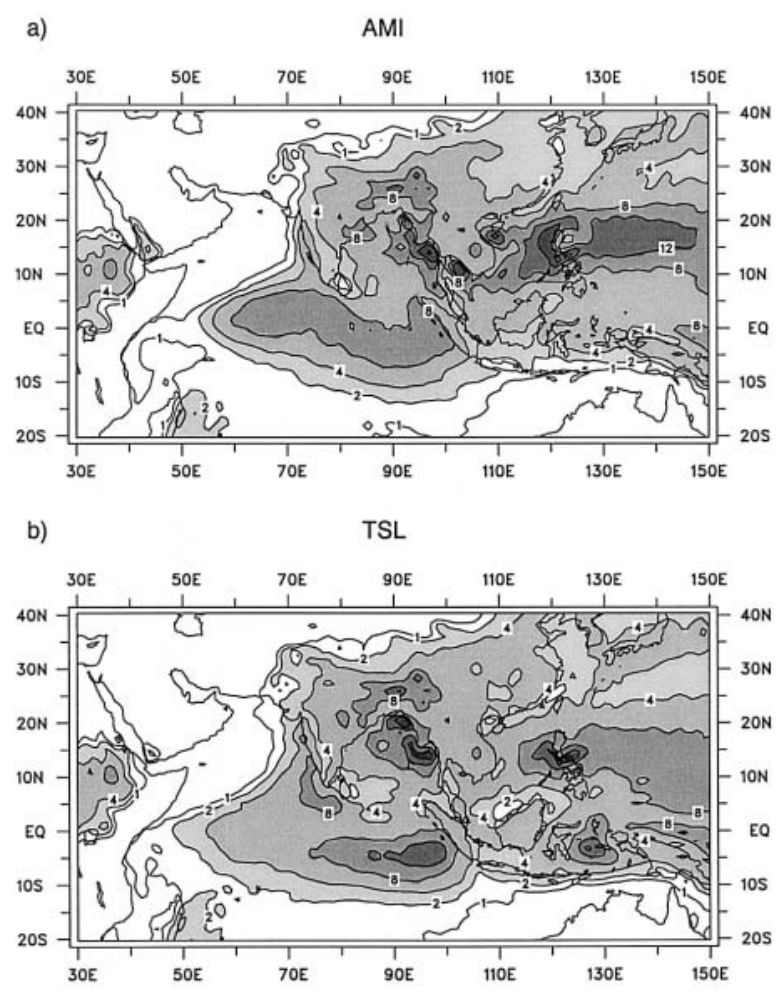

c)

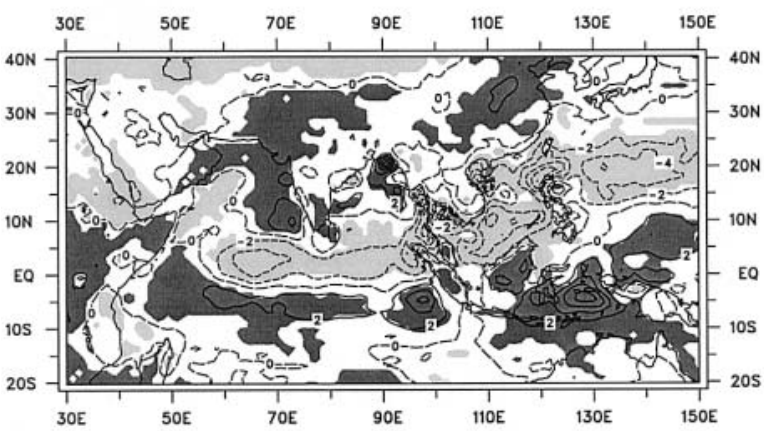

Fig. 5. Seasonal mean of daily precipitation for (a) AMI and (b) TSL, as well as (c) the difference between TSL and AMI. Units are $[\mathrm{mm} / \mathrm{d}]$. The contour lines shown are at 1,2, 4, 8, 12, 16 and $24 \mathrm{~mm} / \mathrm{d}$, and the different shades of grey indicate the intensity of daily rainfall $(\mathrm{a}, \mathrm{b})$. In (c) the contour interval is $2 \mathrm{~mm} / \mathrm{d}$, and the shading indicates the statistical significance of the differences at the $95 \%$-level. 
neous second rainfall maximum to the southwest of India, which indicates the deformation and split of the ITCZ over the Indian Ocean, does not appear in TSL, as illustrated by the negative anomalies in the respective area (Fig. 5c). Further improvements are the stronger precipitation to the west of the Indian subcontinent and over the Bay of Bengal as simulated in TSL. The maximum to the west of Indonesia, however, is too strong. Also over the western Pacific both the magnitude and the geographical distribution of rainfall in TSL are in markedly better agreement with observations than for AMI. Not only is the ITCZ shifted about $10^{\circ}$ further south in TSL, it is also correctly tilted from the southeast to the northwest (the Philippines) instead of from the northeast to the southwest as in AMI (see Fig. 5a).

\subsection{Discussion}

It is somewhat surprising that the quality of the simulation of the seasonal mean aspects of the Indian summer monsoon in particular and of the circulation over Southeast Asia in general, is markedly improved in TSL as compared to AMI, where observed values of the lower boundary forcing have been prescribed. To investigate whether these improvements are related to the initial warm bias of TSL, the differences between the two simulations are compared to the climatic changes of the Indian summer monsoon due to the anticipated increase of the concentrations of the important greenhouse gases predicted by the time-slice experiment (May 2002).

Figure 6 shows the climatic changes of the seasonal mean values for various meteorological variables as obtained from the time-slice experiment, i.e., the differences between the long-term mean values for the future climate (period 2060-2089) and for the present-day climate (period 1970-1999). According to this, the anticipated increase in the greenhouse gas concentrations leads to a general warming in the region of interest, including Southeast Asia and the Indian Ocean (Fig. 6a). The warming is generally stronger over land than for the oceans, and the warming is relatively weak $\left(<2^{\circ} \mathrm{C}\right)$ over the Indian Ocean south of about $10^{\circ} \mathrm{S}$ and the western Pacific between about 10 and $20^{\circ} \mathrm{N}$. As a consequence, the temperature difference between the Indian Ocean and the land areas to the north is enhanced by $1-2^{\circ} \mathrm{C}$ in the future. One, therefore, should expect an intensification of the Indian summer monsoon in the future (e.g., Krishnamurti and Ramanathan 1982).

The time-slice experiment predicts, however, a general reduction of the monsoon circulation in the future. This is mainly due to changes in the upper troposphere, with pronounced westerly wind anomalies over southern India and much of the Indian Ocean (Fig. 6d), while in the lower troposphere easterly wind anomalies can be found over the Indian peninsula (Fig. 6c). According to May (2002), the reduction of the monsoon circulation is due to the El Niño-like warming pattern in the tropical Pacific (Roeckner et al. 1999), as the westerly winds in the lower troposphere, as well as the easterly winds in the upper troposphere in the Indian region, have been found to be markedly reduced during El Niño events (e.g., $\mathrm{Ju}$ and Slingo 1995). Apparently, in the upper troposphere the remote forcing by the "quasipermanent" El Niño conditions dominates the climatic change, while in the lower troposphere the corresponding remote response is partly compensated for by the effect of the enhanced temperature contrast between the ocean and land areas. Over the subtropical western $\mathrm{Pa}-$ cific the climatic change shows an anomalous anticyclonic flow pattern in the lower troposphere (Fig. 6c), accompanied by a cyclonic flow pattern at the upper level with the southward shift of the subtropical jet over East Asia superimposed on the northern side (Fig. 6d). As a consequence, the East Asian monsoon is enhanced in the future. These changes in the large-scale flow are related to the increase of the atmospheric pressure over the western $\mathrm{Pa}$ cific centred between about 16 and $28^{\circ} \mathrm{N}$ (not shown), which, in turn, is due to the El Niñolike warming pattern.

As for precipitation, the time-slice experiment reveals a northward shift of the ITCZ over the Indian Ocean, as well as a equatorward shift of ITCZ over the western Pacific combined with an intensification of the rainfall associated with the ITCZ (Fig. 6b). Further, precipitation is enhanced in those parts of the Indian region, where the rainfall is generally rather strong during the monsoon season, namely to the west of the Indian peninsula, and 


\section{Climatic change $2060-2089$ vs. $1970-1999$}
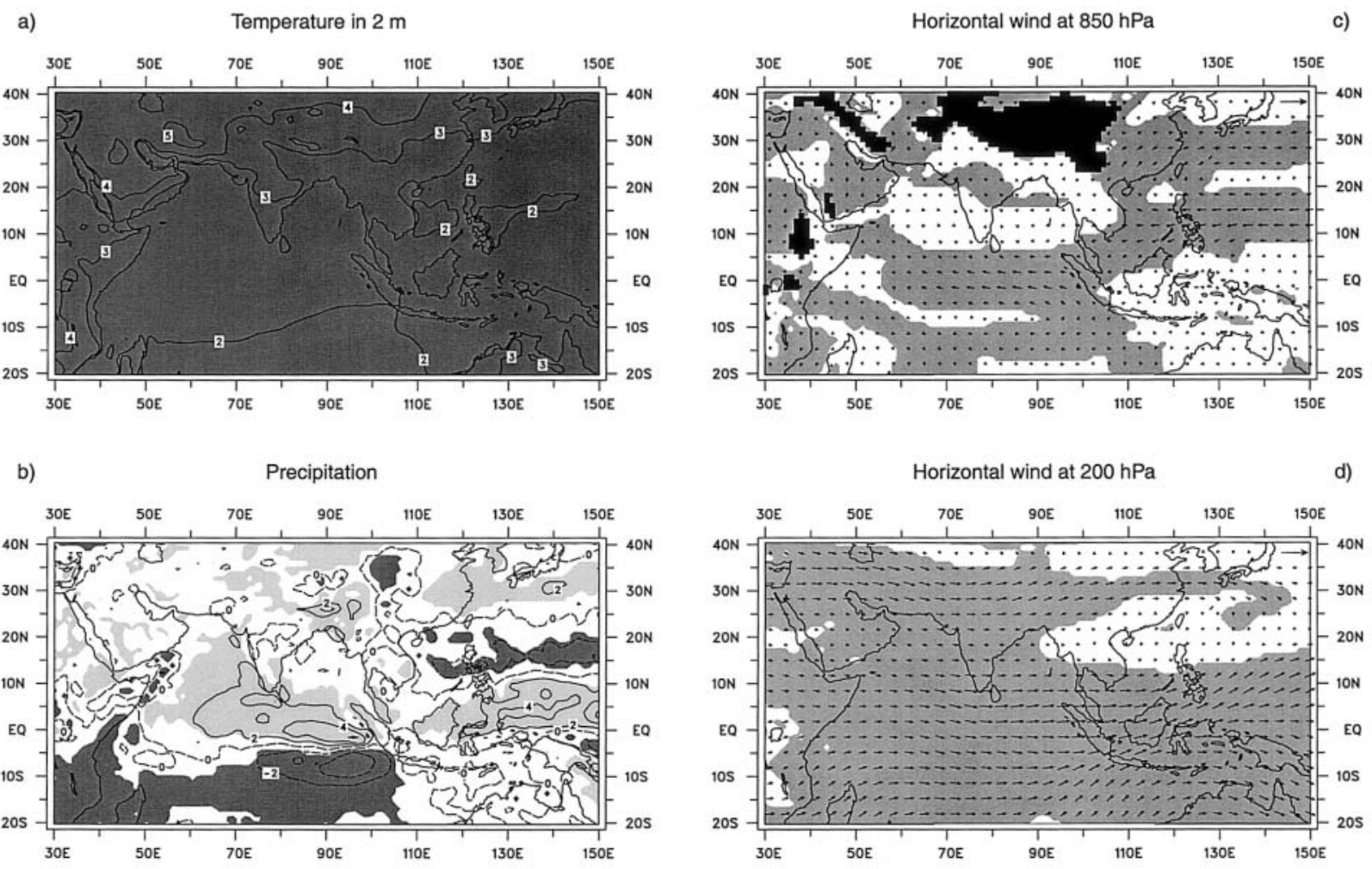

Fig. 6. Climatic change between the periods 2060-2089 and 1970-1999 as obtained from the timeslice experiment (see Section 2) for the seasonal means (June, July, August and September) of (a) the temperature at $2 \mathrm{~m}$, (b) daily precipitation, (c) the horizontal wind at $850 \mathrm{hPa}$, and (d) the horizontal wind at $200 \mathrm{hPa}$. Units and contour intervals as in the corresponding preceding figures, i.e., the differences between the different data sets. The shading indicates the statistical significance of the differences at the $95 \%$-level.

in northeast India and Bangladesh. The increase of the monsoon rainfall is related to an intensification of the atmospheric moisture transport into the Indian region (May 2002). To the west of the Indian peninsula, precipitation is further increased due to the relatively strong warm temperature bias in the eastern Arabian Sea (see Fig. 1c), leading to enhanced evaporation and local production of precipitation near the west coast. The changes over the western Pacific are, on the other hand, the consequence of the enhanced convergence of the atmospheric moisture fluxes in the ITCZ accompanied by more pronounced moisture flux divergence and, hence, reduced rainfall in the adjacent (subtropical) areas (May and Roeckner 2001). The reduced precipitation over the subtropical western Pacific is associated with reduced la- tent heat release and, hence, an increase of the atmospheric pressure in this area.

Apparently, the initial warm bias can explain some of the improvements in TSL compared to AMI, which have been discussed in the preceding sections. These are, for instance, the relatively strong precipitation in the Indian region (see Fig. 5c) and, hence, the reduced warm temperature bias over India (see Fig. 1c). It also accounts for the somewhat weaker westerly low-level monsoon flow over southern India (see Fig. 3a) and the reduction of the upperlevel easterly winds in this area (see Fig. 3b). The latter means, however, a deterioration of the simulation compared to AMI. The initial warm temperature bias can also explain the improvements in TSL over the western Pacific. For example, the equatorward shift of the ITCZ 
to the east of the Philippines (see Fig. 5c) and the resulting anomalous anticyclonic circulation pattern in the lower troposphere over the subtropical western Pacific, particularly improving the simulation of the East Asian monsoon (see Fig. 3a). In the upper troposphere the warm temperature bias accounts for the westerly wind anomalies over the western Pacific to the south of about $15^{\circ} \mathrm{N}$, but not for the easterly anomalies further north (see Fig. 3b). The differences between the two simulations reveal an anomalous cyclonic flow pattern over the western Pacific in the upper troposphere, which is dynamically consistent with the anticyclonic flow anomaly at the lower level. For the climatic change the anomalous flow patterns at the two levels are not dynamically consistent, however, since on the northern side the upperlevel climatic change is dominated by a southward shift of the subtropical jet indicated by the westerly wind anomalies. The southward displacement of the subtropical jet stream is part of the global climatic change pattern related to the contraction of the Hadley cells in the future (May and Roeckner 2001).

A closer look at the two difference maps for precipitation reveals a number of marked dissimilarities over the ocean areas. Over the western Pacific, i.e., between about 10 and $25^{\circ} \mathrm{N}$ and over the South China Sea, the decrease of precipitation in TSL compared to AMI (see Fig. 5c) is considerably stronger than the reduction of rainfall for the future climate (see Fig. 6b). This indicates the importance of other factors than the initial warm bias, namely the too cold SSTs in these areas in TSL (see Fig. 1c). Over the western Pacific this actually means an improvement compared to AMI, while over the South China Sea the simulation of precipitation is deteriorated in TSL (see Figs. 4 and 5). Over the Indian Ocean the difference between TSL and AMI is characterized by a southward shift of the ITCZ, indicating another improvement in TSL, while the climatic change shows the opposite behaviour. Apparently TSL simulates the convective activity associated with the ITCZ over both the western Pacific and the Indian Ocean in better agreement with observation than AMI, although the underlying SSTs deviate from the observed state, which has been prescribed as lower boundary forcing in AMI. The mechanism involved is possibly the connection between the tropical western Pacific and the tropical Indian Ocean via the Walker circulation (e.g., Webster 1983). That is, the southward shift of the ITCZ over the western Pacific leads as well to a southward shift of the ITCZ over the Indian Ocean. The initial southward shift of the area with strong convective activity over the tropical western Pacific itself presumably involves both processes inherent to the (simulated) atmosphere and processes in the ocean, affecting the structure of the lowlevel flow and, accordingly, of the convergence of the atmospheric moisture flux and the convective activity over the tropical Pacific in relation to the underlying SSTs.

\section{Subseasonal variability}

In this section some aspects of the subseasonal variability of the Indian summer monsoon are investigated by inspecting the most prominent patterns of the day-to-day variability of both the large-scale circulation and precipitation over India and other regions in Southeast Asia in the period June through September.

\subsection{Large-scale circulation}

During the established phase of the Indian summer monsoon the circulation undergoes pronounced variations, usually referred to as "active/break cycles," which also affect the precipitation distribution in India and other parts of Southeast Asia (see Section 1). To describe the most prominent fluctuations of the largescale circulation from day to day, an empirical orthogonal function (EOF) analysis has been performed on the basis of the horizontal wind at $850 \mathrm{hPa}$ given two times daily, i.e., at 00 and $12 \mathrm{UTC}$ in the area $\left(20^{\circ} \mathrm{S}-40^{\circ} \mathrm{N}, 60-120^{\circ} \mathrm{E}\right)$.

The first three EOFs based on the reanalyses are shown in Fig. 7. The most prominent EOF ("EOF-1") is dominated by a band of westerly wind anomalies reaching from the Arabian Sea over the Indian peninsula and the Bay of Bengal into Thailand, Indochina, and the western tropical Pacific (Fig. 7a). This pattern is accompanied by a cyclonic flow over Bangladesh and the northern part of the Bay of Bengal. By this, EOF-1 depicts a strengthening or weakening, respectively, of the mean flow in this area during the monsoon season (see Fig. $2 a)$, depending on the phase of this mode. This 
Horizontal wind at $850 \mathrm{hPa}-\mathrm{ERA}$
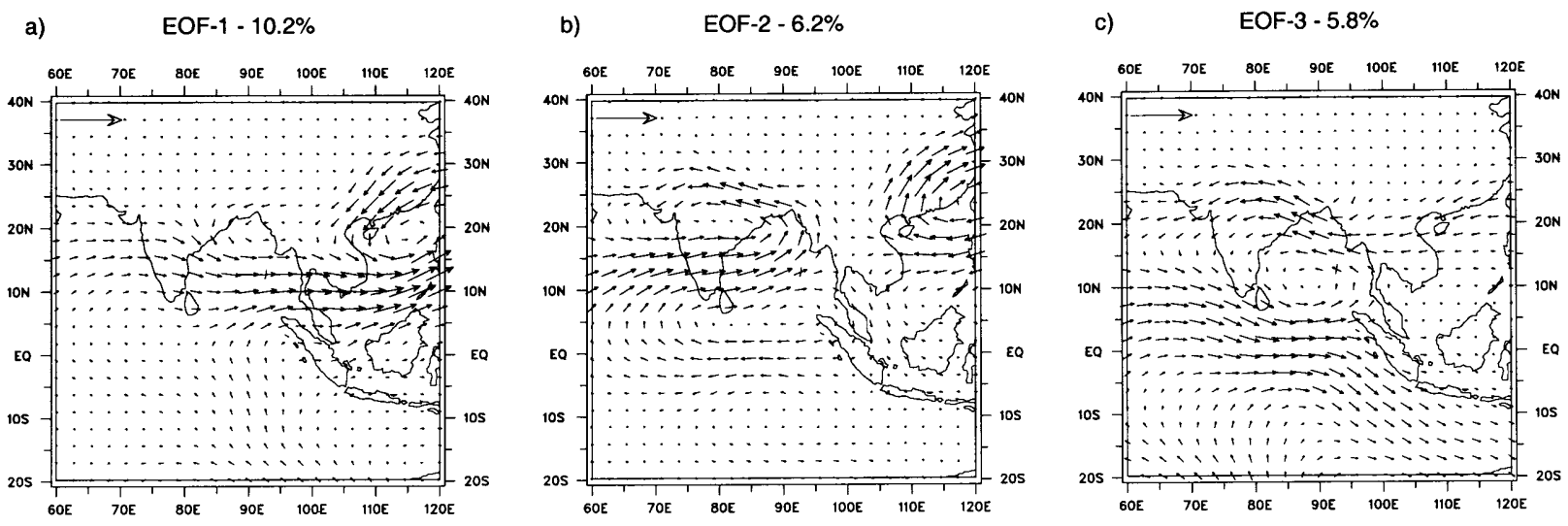

Fig. 7. First three EOFs of the 2 times daily values of the horizontal wind at 850 hPa for ERA including June, July, August and September. The variance explained by each mode is also given. Units are arbitrary. The arrows in the upper left corner represent 28 units.

variation of the Indian summer monsoon is accompanied by a cyclonic flow pattern over southern China and the South China Sea. EOF-2 is also characterized by an enhancement of the westerly flow over the Indian peninsula, accompanied by southerly wind anomalies over the Bay of Bengal and easterly wind anomalies over northern India (Fig. 7b). The latter leads to a stronger inflow into Bangladesh and northern India. The easterly wind anomalies around the equator indicate a northward shift of the ITCZ over the Indian Ocean (see Fig. 2a). In this case an anticyclonic flow pattern is found over southern China and the South China Sea. EOF-3 is dominated by a cyclone centred over the southern Bay of Bengal (Fig. 7c), leading the westerly winds to the south around the Indian peninsula and causing an enhanced inflow into Bangladesh and northern India. According to this, the first three EOFs based on ERA are in quite good agreement with those derived from the NCEP/NCAR reanalyses for the period 1958-1997, except for the swapped order of the second and third EOF (Sperber et al. 2000). As for EOF-1, however, ERA does not reveal easterly wind anomalies to the south of the equator, indicating a northward shift of the ITCZ over the Indian Ocean.

The corresponding EOFs for the two simulations are given in Fig. 8 (AMI) and Fig. 9 (TSL), respectively. The first EOFs derived from the two simulations (Figs. 8a and 9a) are very similar to EOF-1 based on ERA (see Fig. 7a). The variance explained by the respective modes is somewhat larger in the simulations than for ERA, i.e., $10.2 \%$ for ERA, $11.4 \%$ for AMI, and $13.1 \%$ in TSL. This should be expected, since on one hand the period covered in TSL is twice as long as for AMI and ERA and, on the other hand, ERA may include additional artificial day-to-day fluctuations arising in the process of analysing the incoming observational data. The simulations also reveal modes corresponding to ERA's EOF-2 (see Fig. 7b), that are EOF-4 for AMI (not shown) and EOF-3 for TSL (Fig. 9c), while only AMI shows a mode similar to ERA's EOF-3 (see Fig. 7c), that is EOF-2 (Fig. 8b). However, EOF-2 based on TSL (Fig. $9 \mathrm{~b}$ ) is quite outstanding in the sense that it does not have any counterpart in either AMI or ERA. EOF-3 based on AMI (Fig. 8c), on the other hand, is quite similar to TSL's EOF-4 (not shown).

In order to assess the dominant time scales of the different patterns of the day-to-day variability, the spectra of the time series of the principal components have been computed for the different EOFs (not shown). For ERA, the spectrum for EOF-1 is characterized by rather strong power in the time range between 30 and 60 days, with a dominant peak at about 40 days. The spectrum also reveals rather strong power on time scales between 10 and 20 days. These are the preferred time scales of observed 


\section{Horizontal wind at $850 \mathrm{hPa}-\mathrm{AMl}$}
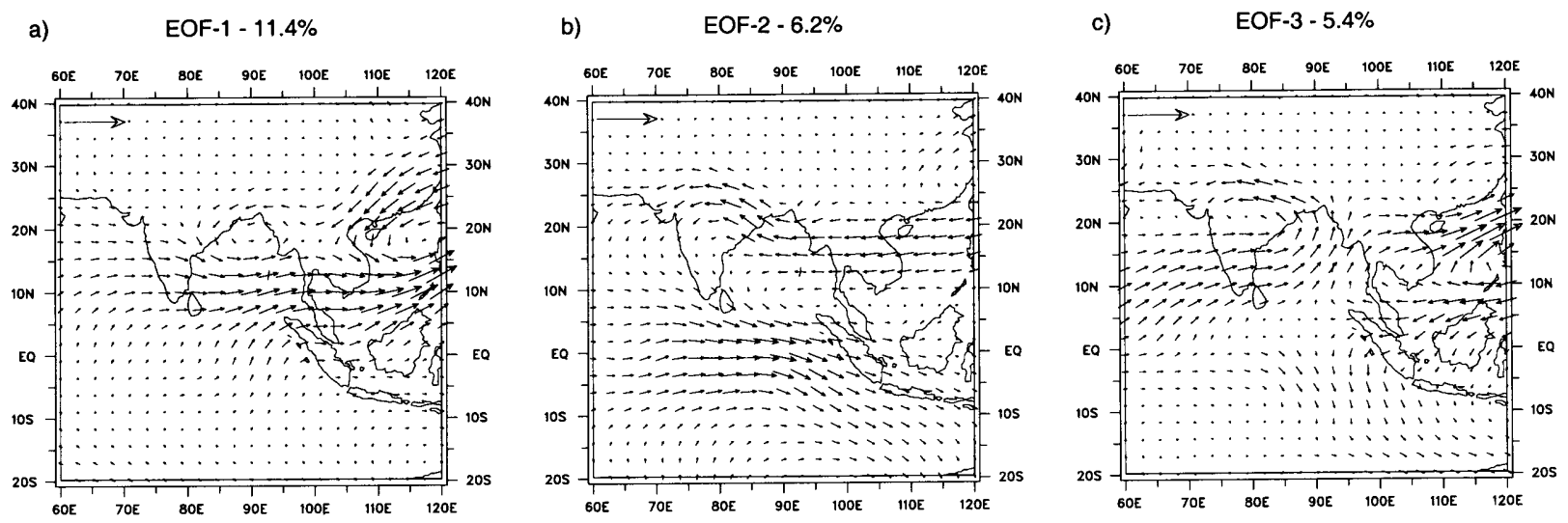

Fig. 8. As Fig. 7, but for AMI.

\section{Horizontal wind at $850 \mathrm{hPa}-\mathrm{TSL}$}

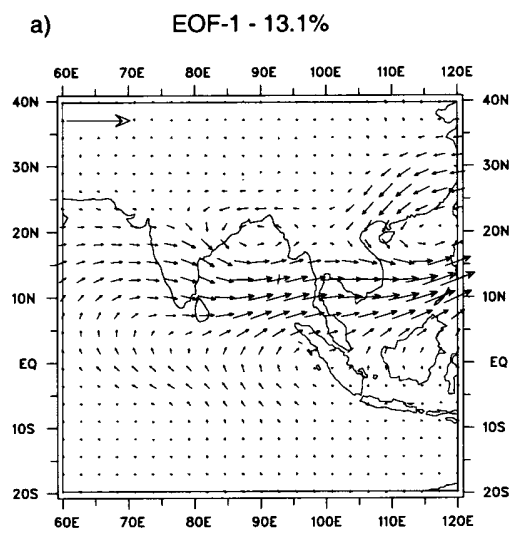

b)

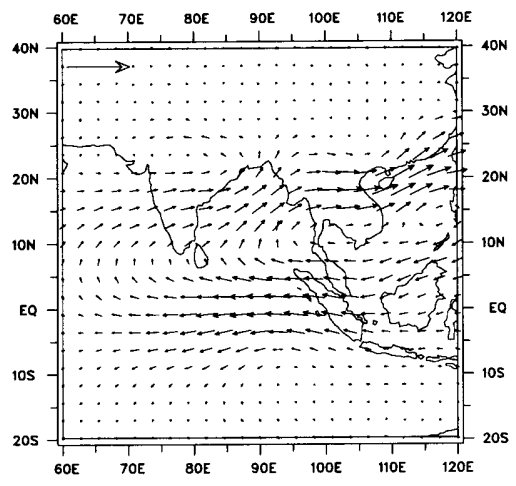

c) EOF-3 - $5.5 \%$

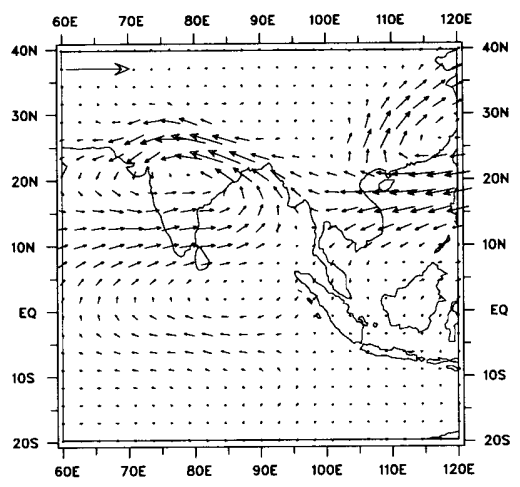

Fig. 9. As Fig. 7, but for TSL.

fluctuations in both convection and the circulation in the Indian region (e.g., Krishnamurti and Bhalme 1976; Sikka and Gadgil 1980; Gadgil and Asha 1992). For the simulations, the respective spectra are characterized by considerably more power at the long periods around 60 days, but less power on the time scales between 10 and 20 days. This particularly is the case for TSL, which shows a red spectrum except for the time range between 30 and 60 days. The spectra for ERA's EOF-2 and for ERA's EOF-3 are characterized by rather strong power on time scales between 20 and about 34 days, indicating that only EOF-1 is associated with the day-to-day fluctuations on time scales longer than 30 days. However, the simulations do not reveal a similar temporal dependence for the higher-order EOFs.

\subsection{Precipitation}

To further investigate the nature of the dayto-day variations of the Indian summer monsoon, an EOF analysis also has been performed for daily precipitation covering two areas; that are the entire Indian region covering both land and ocean areas $\left(8.5^{\circ}-30^{\circ} \mathrm{N}, 65-100^{\circ} \mathrm{E}\right)$ and the land areas of India and Bangladesh.

Figure 10 shows the first three EOFs for the entire Indian region on the basis of the re-analyses. According to this, three "centers 


\section{Precipitation - ERA}

a)

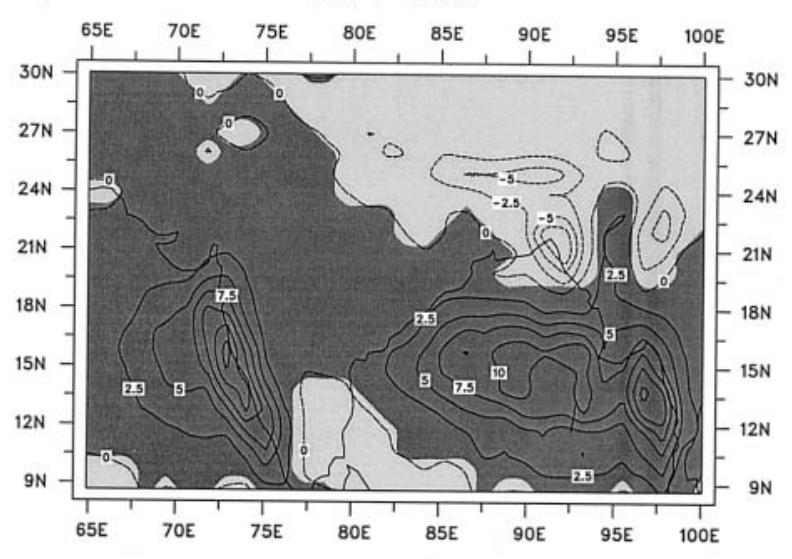

b)

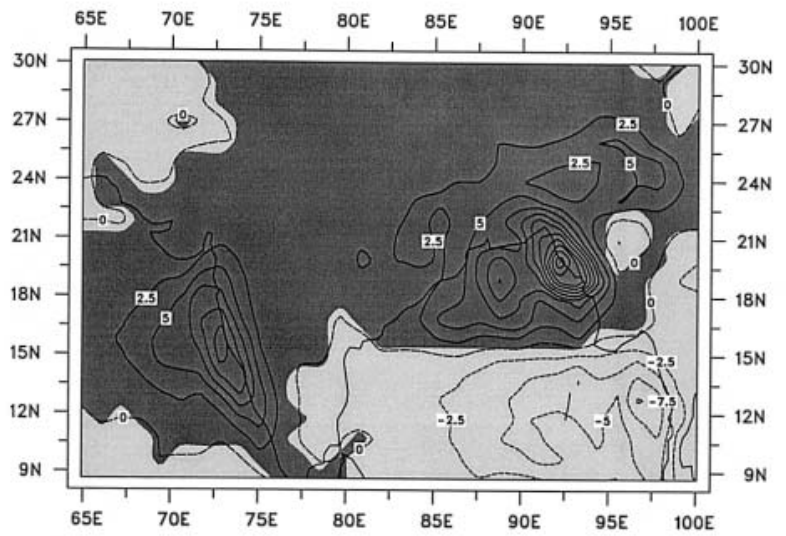

c) EOF-3-6.6\%

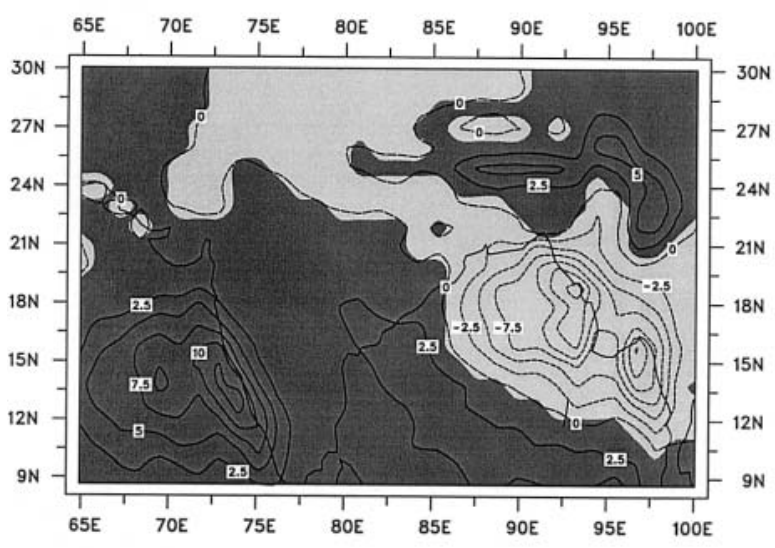

Fig. 10. First three EOFs of daily precipitation for ERA including June, July, August and September for the Indian region. The variance explained by each mode is also given. Units are arbitrary and the contour interval is 2.5 . of action" dominate the most prominent EOF (EOF-1; Fig. 10a). Two of them have the same sign, one of them located to the west of the Indian peninsula and over the Western Ghats and the other one over the Bay of Bengal (except over the very northern part) and Burma, further extending to the northwest over the northern part of the Indian peninsula. Maximum values occur just to the west of the respective landmasses, i.e., to the west of the Western Ghats and the Arakan Mountains in Burma, respectively. The third center with the opposite sign and a magnitude, which is about $50 \%$ smaller than for the two other centers, includes the most northern part of the Bay of Bengal, Bangladesh and the Himalayan foothills. These three centers coincide with those regions, where the rainfall maxima occur during the monsoon season (see Fig. 5). Apparently, during its positive phase this prominent mode is associated with an enhancement of the rainfall maxima embedded in the band of westerly winds extending from the Arabian Sea over southern India and the Bay of Bengal into the eastern parts of Southeast Asia (see Fig. 2a). But at the same time, the maximum related to the southerly flow over the most northern part of the Bay of Bengal into Bangladesh and northeastern India is decreased. Also, for EOF-2, ERA shows three centers of action (Fig. 10b). These are found in locations similar to those for EOF-1, but unlike to EOF-1, the positive rainfall anomalies to the west of the Indian peninsula go along with negative anomalies over both the southern part of the Bay of Bengal and farther to the north. The two centers in the eastern part of the Indian region also are separated at about $15^{\circ} \mathrm{N}$, several degrees further south than for EOF-1. As for EOF-3, the distribution is characterized by a more detailed structure, as the negative rainfall anomalies over the northeastern part of the Bay of Bengal are accompanied by positive anomalies both to the southwest and to the north (Fig. 10c).

The first EOF obtained from the GPCP data set for the period 1997-2001 (Fig. 11; see Section 3.3) is very similar to ERA's EOF-1 with the same three centers of action. The only marked difference is that the strength of the center near the west coast of the Indian peninsula is considerably weaker than for ERA (see Fig. 10a). However, the higher-order EOFs dif- 


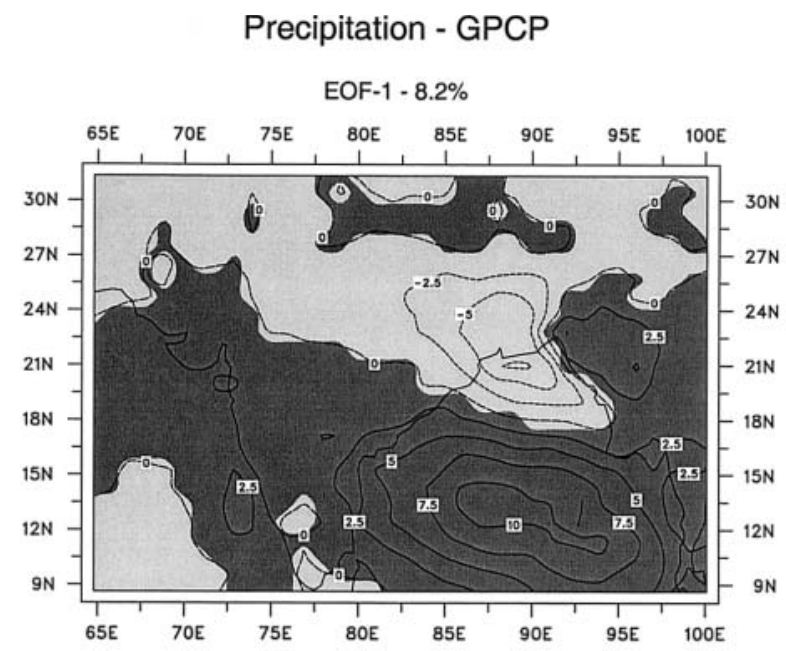

Fig. 11. As Fig. 10a, but for the GPCP data set for the period 1997-2001.

fer substantially between the two data sets (not shown). This suggests that the first EOF of precipitation in the Indian region is very robust, while the structure of the higher-order EOFs can depend either on the period of the data entering the EOF-analysis or on the data source itself.

The two most prominent EOFs of precipitation are very similar for the two simulations, both for the entire Indian region and for the land areas of India and Bangladesh (see below). Therefore, only the EOFs obtained from AMI will be shown and discussed in the following. The most prominent EOF obtained from the simulation (Fig. 12a) is characterized by a spatial structure very similar to ERA's EOF-1 (see Fig. 10a), because the corresponding centers of action are located in about the same areas. One marked difference to the re-analyses, however, is the fact that the center to the west of the Indian peninsula is considerably weaker (by about a factor of 3) than the center over the southern part of the Bay of Bengal, whereas in ERA these two centers have about the same magnitude. Furthermore, the western center is much more confined to a narrow band along the Indian west coast. Another difference with respect to ERA is that in the simulation the anomalies over the northern part of the Bay of Bengal are mainly found over the ocean, while in ERA the maximum anomalies occur over the
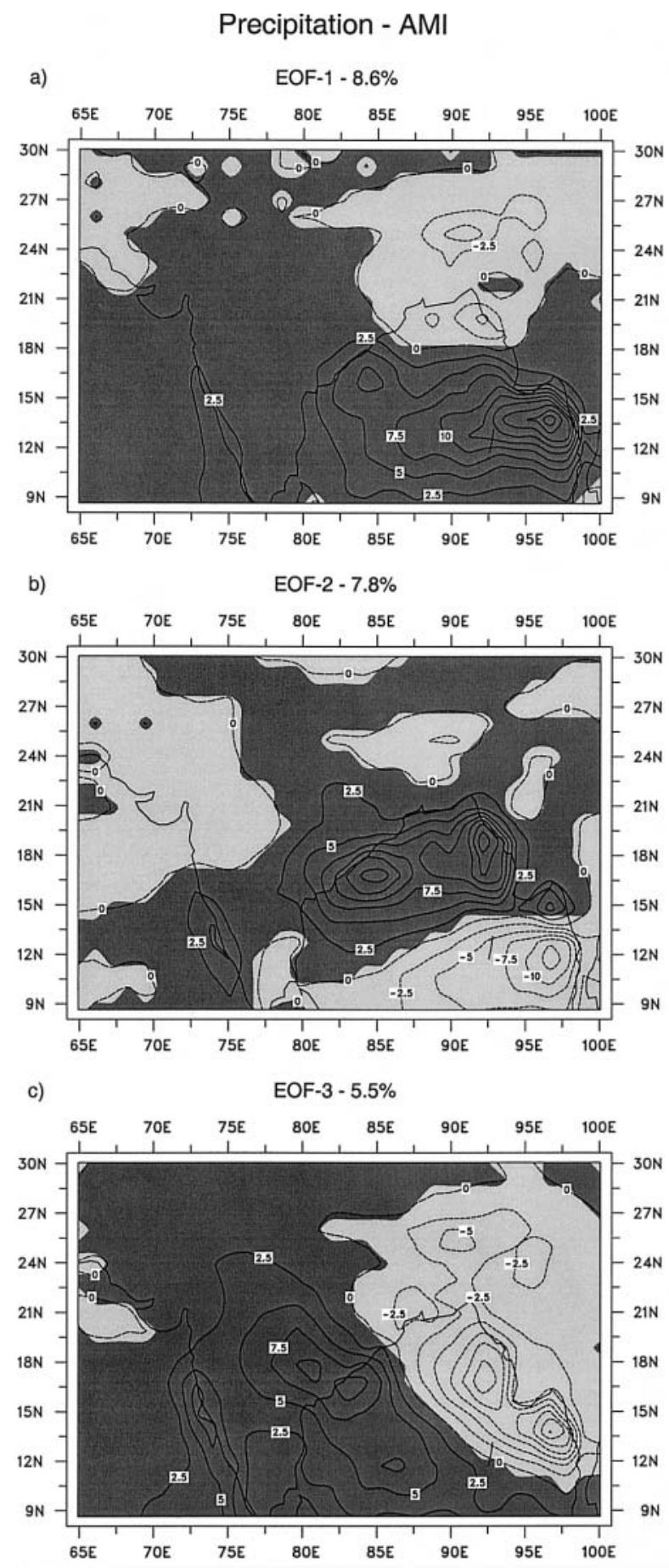

Fig. 12. As Fig. 10a, b, but for AMI.

land area to the north. This deviation is presumably also related to a difference in the simulated spatial structure of precipitation, because the respective rainfall maximum occurs 
over the ocean in the model (see Fig. 5a) and over land in ERA.

As for EOF-2, the simulation (Fig. 12b) reveals the same kind of similarities and dissimilarities with ERA (see Fig. 10b) as EOF-1, namely a considerably smaller magnitude of the western center of action and the fact that the northern part of the eastern center is located over the Bay of Bengal and not over the land area to the north. In particular, the model simulates a westward extension of the western half of this center. The main difference between EOF-3 based on the simulation with ERA's EOF-3 are the relatively strong positive anomalies over the northeastern part of the Indian peninsula (Fig. 12c). AMI's EOF-3 also reveals negative anomalies over the Himalayan foothills, whereas positive anomalies can be found over this area in ERA (see Fig. 10c). Further, the underestimation of the variability associated with the western center to the west of the Indian peninsula by the model is much less severe than for EOF-1 and EOF-2.

As indicated by the EOFs shown above, the day-to-day variations of precipitation in the entire Indian region are to a large extent dominated by variations over the oceans. But the most important aspect regarding the socioeconomic impact of the Indian summer monsoon is the rainfall occurring over land. Therefore, EOFs of the daily precipitation have also been computed considering the areas of India and Bangladesh, not considering the mountainous regions in the very north of India.

Based on the re-analyses, EOF-1 reveals two areas with negative anomalies, namely the northeastern part of the area including Bangladesh, the valleys of the Ganges and Brahmaputra in India, and the southeastern tip of India (Fig. 13a). The variations over the northeastern part of the area dominate the pattern clearly. Relatively large positive anomalies are found on the west coast of the Indian peninsula (here the magnitude is about one third of the maximum anomalies in the northeast) and in central India. EOF-2, on the other hand, is characterized by anomalies of the same (positive) sign over almost the entire area (Fig. 13b). Negative anomalies can be found only over the southeastern tip of India and small regions in the very northern part of India. The strongest positive anomalies are located on the west
Precipitation - ERA

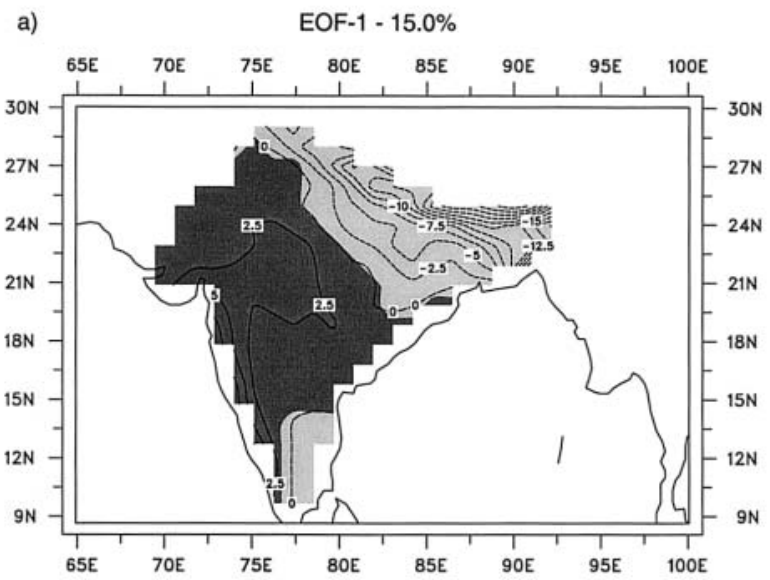

b)

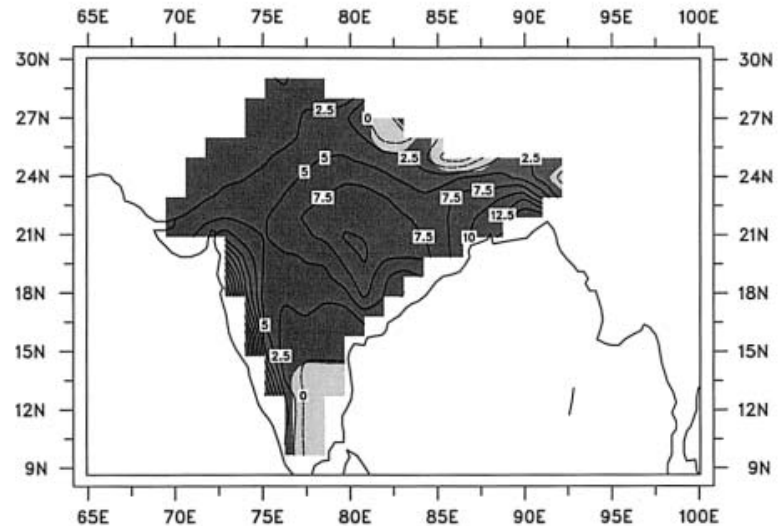

c)

EOF-3 $-8.7 \%$

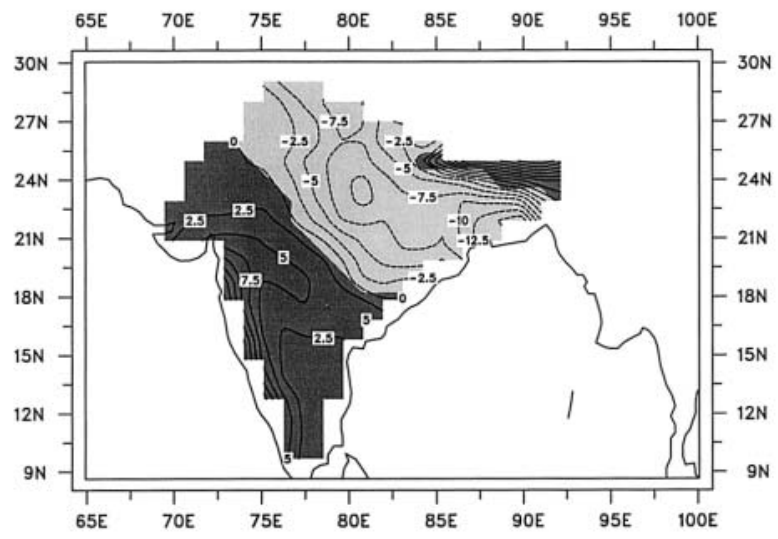

Fig. 13. As Fig. 10, but for India and Bangladesh, not considering the mountainous regions in the very north of India. 


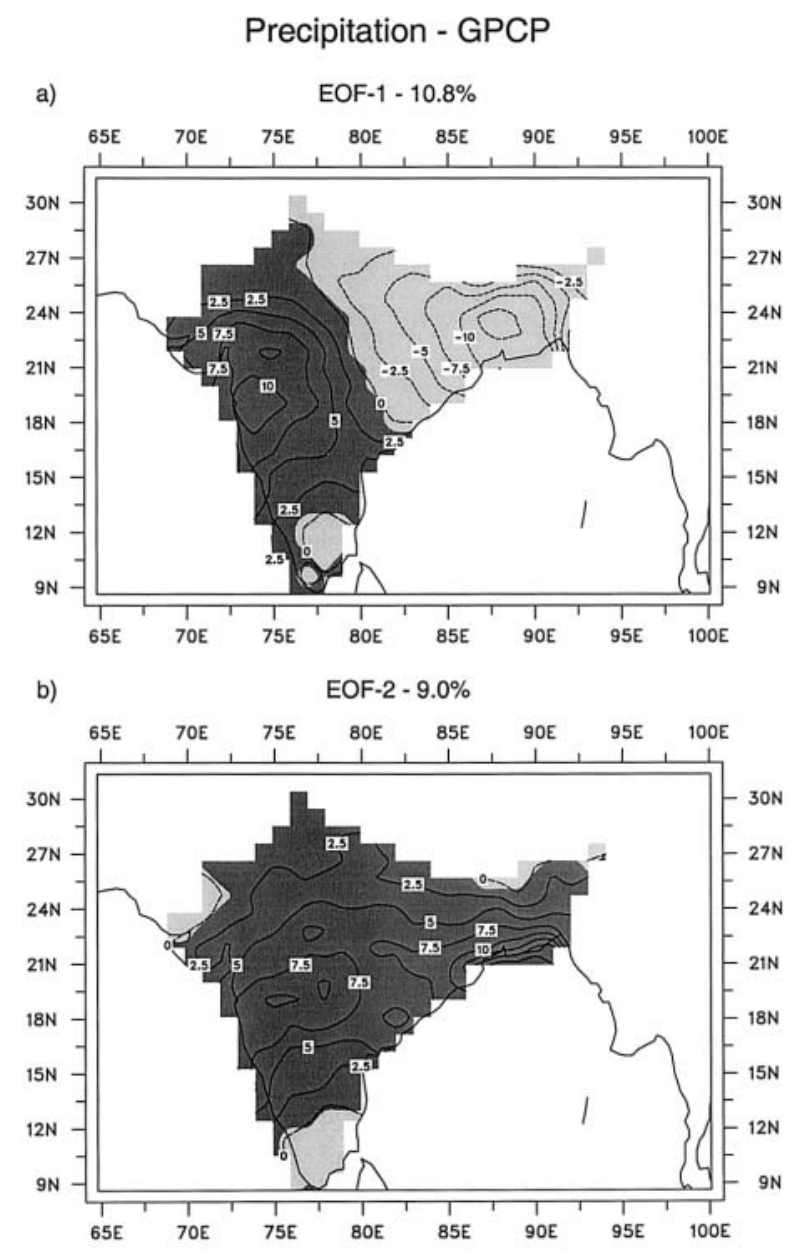

Fig. 14. As Figs. 13a, b, but for the GPCP data set for the period 1997-2001.

coast and over Bangladesh, with the latter center of action extending westward over a large portion of northern India. Finally, EOF-3 reveals positive anomalies over the western and southern parts of India and in the Brahmaputra valley, while in the rest of the area, in particular in the Ganges valley negative anomalies occur (Fig. 13c). As for the areas of India and Bangladesh, the first two EOFs based on the GPCP data set (Fig. 14) are very similar to ERA's two most prominent EOFs, indicating the robustness of these modes. In GPCP's EOF1 , however, the western center of action is not so much limited to the west coast, but covers most of the western Indian peninsula (Fig. 14a). Also for EOF-2 (Fig. 14b) the strength of the center of action on the west coast of the
Indian peninsula is considerably reduced compared to ERA.

The corresponding (the same order) EOFs for the two different areas reveal some similarities. Both EOF-1, for instance, are characterized by positive anomalies on the west coast of the Indian peninsula and negative ones in Bangladesh and northeastern India (see Figs. 10a and 13a). These two areas actually appear to be key regions with regard to the day-to-day variations of the Indian summer monsoon, as almost all the EOFs shown reveal centers of action in these regions. As an objective measure for the degree of similarity between all pairs of EOFs derived for the two different areas, the temporal correlation coefficients between the respective time series of the principal components have been computed. The highest correlation has been found for the pair of EOF-2 with a value of 0.42 . For the pair of EOF-1 and the pair of EOF-3, the correlation coefficients are 0.33 and 0.25 , respectively.

The EOF-1 based on the simulation reveals the same general structure: negative and positive anomalies, respectively, are located in the same regions as in ERA's EOF-1 (see Fig. 13a). Negative anomalies occur in Bangladesh and northeastern India and over the southeastern tip of the Indian peninsula, and positive ones occur on the west coast of the Indian peninsula and in central India (Fig. 15a). The magnitude of the anomalies in central India, however, is considerably larger (by about a factor of 4) than for the corresponding anomalies in ERA, while the magnitude of the anomalies on the west coast is markedly smaller. Further, the extension of the area with pronounced positive anomalies on the west coast is much smaller in the simulation. Apparently, the area with the strongest day-do-day variability is shifted inland in the simulations. For EOF-2, however, the simulation reveals a quite different structure than both ERA's EOF-2 (see Fig. 13b) and ERA's EOF-3 (see Fig. 13c). Negative anomalies can be found over the eastern and southern parts of the area and positive ones over the northwestern part (Fig. 15b). The three centers of action are located in the northeastern part of the area, over the eastern and over the northwestern Indian peninsula, with the latter center being somewhat weaker in TSL than in AMI. 


\section{Precipitation - AMI}
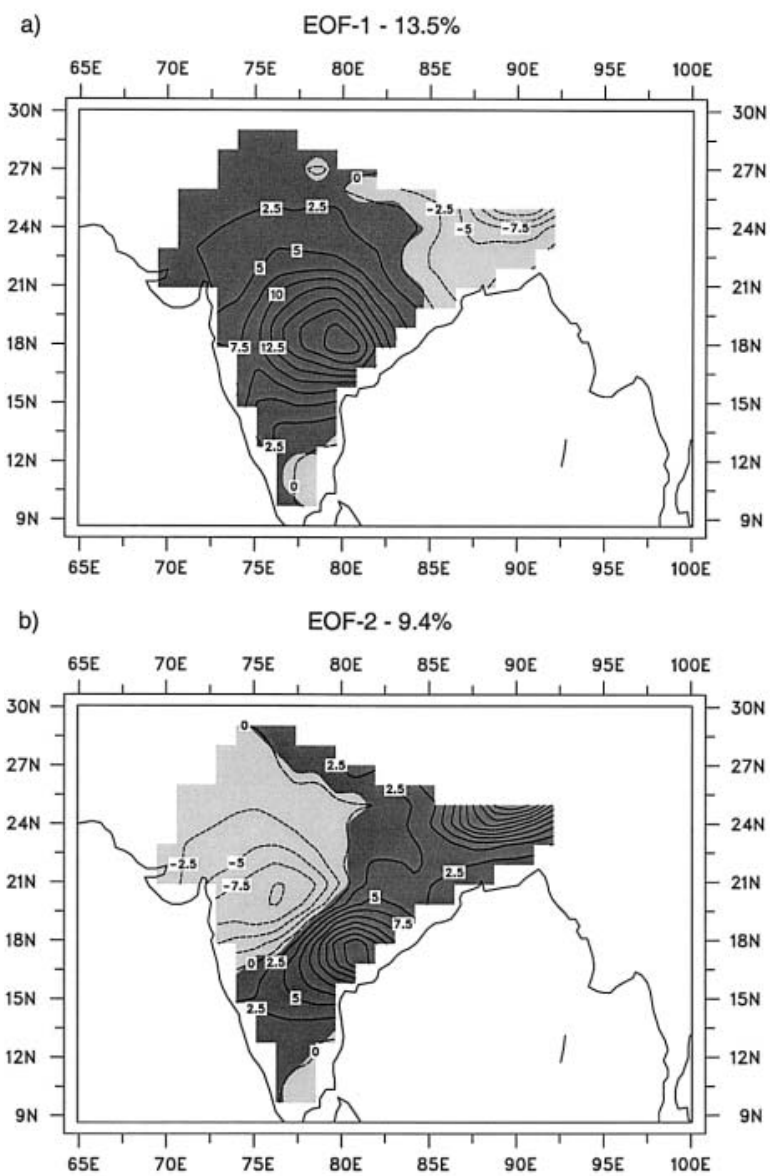

Fig. 15. As Figs. 13a, b, but for AMI.

In contrast to ERA, the EOFs with the same order for the two different areas reveal very few similarities for the simulation. Instead, relatively high correlations can generally be found, when the order of the EOF for the entire Indian region is higher than for the EOF for the smaller area. The most outstanding example for this is found for AMI, where the correlation between EOF-1 for the small (see Fig. 15a) and EOF-3 for the large area (see Fig. 12c) has a value of 0.45 .

\subsection{Discussion}

In contrast to the seasonal mean characteristics of the Indian summer monsoon (see Section 3.4), the modes describing the subseasonal variability of the Indian summer monsoon do not reveal any marked differences between the two simulations. As for precipitation, the two sets of EOFs obtained from AMI and TSL are very similar, while for the low-level wind TSL's EOF-2 is quite different to the EOFs based on AMI and on ERA. But as the variance explained by this mode is only $6.2 \%$, it is hard to judge whether this difference is related to the initial warm temperature bias over the Indian Ocean.

For precipitation, the EOFs based on the simulations are characterized, for example, by a pronounced underestimation of the day-to-day variability near the west coast of the Indian peninsula and to a lesser extent over Bangladesh. Apparently, these EOFs reflect the model's shortcomings in realistically simulating the amount of precipitation near the west coast of the Indian peninsula and over Bangladesh (see Section 3.3). The seasonal mean distributions of daily rainfall indicate, for instance, a severe underestimation of rainfall by ECHAM4 near the west coast of the Indian peninsula and to some extent over Bangladesh (see Fig. 5). This idea is supported by the results based on an independent observational data set of daily precipitation, namely the GPCP data set for the period 1997-2001. The EOFs derived from GPCP are also characterized by an underestimation of the day-to-day variability near the west coast of the Indian peninsula, and also the respective seasonal mean values show a general underestimation of precipitation in this area (see Fig. 5). Therefore, the EOFs based on the simulations have by and large more similarities with the respective EOFs in GPCP than with those derived from ERA.

\section{Summary and conclusions}

In this paper the simulation of various aspects of the Indian summer monsoon with the ECHAM4 AGCM at a horizontal resolution of T106 corresponding to about $120 \mathrm{~km}$ is investigated. This includes aspects of the seasonal mean monsoon as well as of subseasonal variations related to active/break cycles of the monsoon. The purpose of the study is twofold: First, the quality of the simulation of these aspects of the Indian summer monsoon by ECHAM4 is investigated. This is done by comparing a simulation with ECHAM4 at T106 for the period 1979-1993 (“AMI”), where observed values of SSTs and sea-ice extent 
have been prescribed as lower boundary forcing, with the ECMWF re-analyses ("ERA") and other observational data sets of precipitation for the corresponding period. This simulation is also compared to another simulation with ECHAM4 at T106 for the period 1970-1999 ("TSL"), where the lower boundary forcing has been prescribed as obtained from a transient climate change simulation with a low-resolution coupled model, namely ECHAM4 at a horizontal resolution of T42 coupled to the OPYC ocean model. By this, the impact of possible errors in the simulation of the SSTs in the tropical oceans in the coupled model, such as the initial warm bias due to the special experimental design of the transient simulation on the Indian summer monsoon, is assessed.

The comparison between AMI and ERA reveals a quite realistic simulation of the seasonal mean aspects of the Indian summer monsoon by the high-resolution version of the
ECHAM4 AGCM, though a number of differences from the re-analyses or the other observational data sets are found. AMI shows, however, marked deficiencies over the western Pacific, which deteriorate, for instance, the simulation of the East Asian monsoon. In TSL the simulation of many aspects of the seasonal mean Indian summer monsoon, and in particular of the large-scale circulation over the western Pacific, are improved compared to AMI. These improvements can be explained by either the initial warm bias of TSL, i.e., the El Niñolike warming in the tropical Pacific and the general warming over the Indian Ocean, or an error of the underlying SSTs in the Pacific basin with too-cold SSTs in the subtropical Pacific. This error is associated with a much more realistic simulation of the ITCZ over the western Pacific and, hence, over the Indian Ocean in TSL. The following table gives an overview of the deficiencies in AMI, whether the particular

\begin{tabular}{|c|c|c|}
\hline Deficiency & Improvement & Reason(s) \\
\hline $\begin{array}{l}\text { Warm temperature bias over the land } \\
\text { areas }\end{array}$ & Yes & $\begin{array}{l}\text { Initial warm temperature bias over } \\
\text { the Indian Ocean }\end{array}$ \\
\hline $\begin{array}{l}\text { Too strong temperature difference between } \\
\text { the Indian Ocean and the land areas to } \\
\text { the north }\end{array}$ & Yes & $\begin{array}{l}\text { Initial warm temperature bias over } \\
\text { the Indian Ocean }\end{array}$ \\
\hline $\begin{array}{l}\text { Underestimation of precipitation in the } \\
\text { Indian region, in particular near the } \\
\text { west coast of the Indian peninsula }\end{array}$ & Yes & $\begin{array}{l}\text { Initial warm temperature bias over } \\
\text { the Indian Ocean }\end{array}$ \\
\hline $\begin{array}{l}\text { Too strong low-level Indian summer } \\
\text { monsoon flow }\end{array}$ & Yes & $\begin{array}{l}\text { Initial warm temperature bias over } \\
\text { the Indian Ocean \& El Niño-like } \\
\text { warming in the tropical Pacific }\end{array}$ \\
\hline $\begin{array}{l}\text { Too weak upper-level Indian summer } \\
\text { monsoon flow }\end{array}$ & No & $\begin{array}{l}\text { El Niño-like warming in the tropical } \\
\text { Pacific }\end{array}$ \\
\hline $\begin{array}{l}\text { Northward shift and deformation of the } \\
\text { ITCZ over the Indian Ocean }\end{array}$ & Yes & $\begin{array}{l}\text { Erroneous SSTs in the western Pacific } \\
\text { (via the Walker circulation) }\end{array}$ \\
\hline $\begin{array}{l}\text { Northward shift and deformation of the } \\
\text { ITCZ over the western Pacific }\end{array}$ & Yes & Erroneous SSTs in the western Pacific \\
\hline $\begin{array}{l}\text { Anomalous cyclonic flow pattern in the } \\
\text { lower troposphere over the western } \\
\text { Pacific }\end{array}$ & Yes & $\begin{array}{l}\text { Erroneous SSTs in the western Pacific } \\
\text { \& initial warm temperature bias } \\
\text { over the western Pacific }\end{array}$ \\
\hline $\begin{array}{l}\text { Anomalous anticyclonic flow pattern in } \\
\text { the upper troposphere over the western } \\
\text { Pacific }\end{array}$ & Yes & $\begin{array}{l}\text { Erroneous SSTs in the western Pacific } \\
\text { \& (only the southern part) initial } \\
\text { warm temperature bias over } \\
\text { the western Pacific }\end{array}$ \\
\hline East Asian monsoon not captured & Yes & $\begin{array}{l}\text { Erroneous SSTs in the western Pacific } \\
\text { \& initial warm temperature bias } \\
\text { over the western Pacific }\end{array}$ \\
\hline
\end{tabular}


deficiency is improved in TSL, and which of the aforementioned mechanisms can explain the respective improvement.

The different mechanisms that explain the generally improved simulation of the Indian summer monsoon in TSL are associated with different regions. The El Niño-like warming pattern covers, for instance, the entire tropical Pacific basin. The erroneous SSTs occur, on the other hand, in the western subtropical Pacific and the South China Sea, while the initial warm temperature bias affects the entire Indian Ocean basin. As these mechanisms possibly interfere with each other, the ideal way to assess the relative importance of the three mechanisms would be a particular sensitivity experiment for each of the mechanisms with the corresponding SSTs prescribed as lower boundary forcing. This would, however, be beyond the scope of this study, which is based on existing data sets, but support for the findings of this study can be found in the scientific literature. In principle the three mechanisms have the same effect on the Indian summer monsoon. Both the El Niño-like warming (e.g., Ju and Slingo 1995) and the positive temperature anomalies in the Indian Ocean just south of the equator (Chandrasekar and Kitoh 1998) lead to a weakening of the Indian summer monsoon. The latter finding is actually supported by observational results from Joseph et al. (1994). The southward shift of the ITCZ over the Indian Ocean in association with the erroneous SSTs may have a similar effect, since the atmospheric source of diabatic heating is located south of the equator. The cold temperature bias over the western tropical Pacific and the South China Sea leads to suppressed convective activity in these regions and, hence, affects the Indian summer monsoon in the same way as a typical El Niño event (Ju and Slingo 1995). These mechanisms compete, however, with other effects of the initial warm temperature bias in TSL. Due to an enhanced atmospheric moisture transport into the Indian region, for instance, the monsoon rainfall is stronger in TSL than in AMI. This actually indicates a strengthening of this particular aspect of the Indian summer monsoon in contrast to the aforementioned weakening effect of the initial warm temperature bias in the time-slice experiment. The relatively strong temperature bias in the eastern Arabian Sea off the west coast of the Indian peninsula may further enhance this effect, due to increased evaporation and local production of precipitation near the west coast. Finally, the depth and the extent of the Eurasian snow cover in spring are reduced, due to the too warm temperatures in this region. This should lead to a strong monsoon circulation in the following summer (e.g., Douville and Royer 1996).

In contrast to the seasonal mean characteristics of the Indian summer monsoon, the patterns associated with the subseasonal variability of the Indian summer monsoon do not reveal any pronounced differences between TSL and AMI. That is, the day-to-day variability is neither affected by the aforementioned initial warm temperature bias nor by the erroneous SSTs in the western Pacific. The most prominent EOFs describing the day-to-day variability of the low-level winds as simulated by ECHAM4 are in very good agreement with ERA, both with respect to the spatial structure and the dominant time scales of these variations. However, for precipitation, the most prominent EOFs based on the simulations are characterized by a significant underestimation of the subseasonal variability near the west coast of the Indian peninsula. This deficiency mainly reflects the general severe underestimation of precipitation in this area by the model. Apart from this shortcoming, the most prominent EOFs based on the simulations have various details in common with those for the observational data sets.

The results presented here show that the time-slice experiment is very well suited to investigate the possible future change of the Indian summer monsoon (and of the East Asian monsoon) due to the anticipated increase in the concentrations of the important greenhouse gases. TSL appears also very well suited for the investigation of the connection between the Indian summer monsoon and ENSO and its possible future change, since the atmospheric circulation over the western Pacific is simulated very realistically. Therefore, it also can be expected that the nature of the coupling between the tropical Pacific and the tropical Indian Ocean via the Walker circulation is simulated well in TSL. This idea is supported by the fact that the equatorward shift of the ITCZ over 
the western Pacific is accompanied by a corresponding shift of the ITCZ over the Indian Ocean. Another positive feature of the highresolution version of the ECHAM4 AGCM is the very realistic simulation of the subseasonal variability of the Indian summer monsoon. This may, on one hand, lead to a rather realistic simulation of extreme precipitation events during the monsoon season (e.g., Stephenson et al. 1999). A reliable prediction of the future change in the characteristics of extreme precipitation events would be of major interest due to the large socio-economic impacts of such events. On the other hand, the realistic simulation of the day-to-day variability may imply (in combination with a strong coupling between the tropical Pacific and Indian Ocean) a potential long-range predictability of the Indian summer monsoon, as there appears to be a common mode of monsoon variability on subseasonal and interannual time scales (Sperber et al. 2000).

\section{Acknowledgements}

I wish to thank the two anonymous referees for their helpful comments on the manuscript. This work was supported by the European Commission through the PROMISE (Predictability and variability of monsoons and the agricultural and hydrological impacts of climate change) project under contract no. EVK2-199900187.

\section{References}

Annamalai, H., J.M. Slingo, K.R. Sperber and K. Hodges, 1999: The mean evolution and variability of the Asian summer monsoon: comparison of ECMWF and NCEP-NCAR reanalyses. Mon. Wea. Rev., 127, 17-1186.

Bacher, A., J.M. Oberhuber and E. Roeckner, 1998: ENSO dynamics and seasonal cycle in the tropical Pacific as simulated by the ECHAM4/ OPYC3 coupled general circulation model. Clim. Dyn., 14, 431-450.

Bengtsson, L., M. Botzet and M. Esch, 1995: Hurricane-type vortices in a general circulation model. Tellus, 47A, 175-196.

Chandrasekar, A. and A. Kitoh, 1998: Impact of localized sea surface temperature anomalies over the equatorial Indian Ocean on the Indian summer monsoon. J. Meteor. Soc. Japan, 76, 841-853.

Dickson, R.R., 1984: Eurasian snow cover versus Indian monsoon rainfall-an extension of the
Hahn-Shukla results. J. Clim. Appl. Meteor., 23, 171-173.

Douville, H. and J.-F. Royer, 1996: Sensitivity of the Asian summer monsoon to an anomalous Eurasian snow cover within the Météo-France GCM. Clim. Dyn., 12, 449-466.

Dümenil, L. and H.-S. Bauer, 1998: The tropical easterly jet in a hierarchy of GCMs and in reanalyses. MPI-Report, $\mathbf{2 4 7}, 45 \mathrm{pp}$.

and E. Todini, 1992: A rainfall-runoff scheme for use in the Hamburg climate model. In J.P. O'Keane (ed.): Advances in Theoretical Hydrology. Elsevier Science Publishers, Amsterdam, 129-157.

Ferranti, L. and F. Molteni, 2000: Ensemble simulations of Eurasian snow-depth anomalies and their influence on the summer Asian monsoon. Quart. J. Roy. Meteor. Soc., 125, 2597-2610.

Gadgil, S. and G. Asha, 1992: Intraseasonal variation of the Indian summer monsoon. J. Meteor. Soc. Japan, 70, 517-527.

Gates, W.L., 1992: The atmospheric model intercomparison project. Bull. Amer. Meteor. Soc., 73, 1962-1970.

Gibson, J.K., P. Kållberg, S. Uppala, A. Hernandez, A. Nomura and E. Serrano, 1997: ERA description. ECMWF Re-analysis Project Report Series, 1, 72 pp.

Giorgi, F. and L.O. Mearns, 1991: Approaches to the simulation of regional climate change: A review. Rev. Geophys., 29, 191-216.

Hahn, D.J. and J. Shukla, 1976: An apparent relation between Eurasian snow cover and Indian monsoon rainfall. J. Atmos. Sci., 33, 24612462.

Houghton, J.T., B.A. Callandar and S.K. Varney (eds.), 1992: Climate Change 1992: The Supplementary Report to the IPCC Scientific Assessment. Cambridge University Press, $198 \mathrm{pp}$.

, L.G. Meira Filho, B.A. Callandar, N. Harris, A. Kattenberg and K. Maskell (eds.), 1996: Climate Change 1995. The Science of Climate Change. Cambridge University Press, $572 \mathrm{pp}$.

Huffman, G.J., R.F. Adler, B. Rudolph, U. Schneider and P.R. Keehn, 1995: Global precipitation estimates based on a technique for combining satellite-based estimates, rain gauge analysis, and NWP model precipitation information. $J$. Climate, 8, 1284-1295.

Joseph, P.V., J.K. Eischeid and R.J. Pyle, 1994: Interannual variability of the onset of the Indian summer monsoon and its association with atmospheric features, El Niño, and sea surface temperature anomalies. J. Climate, 7, 81-105. 
Ju, J. and J. Slingo, 1995: The Asian summer monsoon and ENSO. Quart. J. Roy. Meteor. Soc., 121, 1133-1168.

Krishna Kumar, K., B. Rajagopalan and M.A. Cane, 1999: On the weakening relationship between the Indian monsoon and ENSO. Science, 284, 2156-2159.

Krishnamurthy, V. and J. Shukla, 2000: Intraseasonal and interannual variability of rainfall over India. J. Climate, 13, 4366-4377.

Krishnamurti, T.N. and P. Ardanuy, 1980: The 10 to 20 day westward propagating modes and "breaks in the monsoons". Tellus, 32, 15-26. and H.N. Bhalme, 1976: Oscillations of the monsoon system. Part I: observational aspects. J. Atmos. Sci., 33, 1937-1954.

and Y. Ramanathan, 1982: Sensitivity of the monsoon onset to differential heating. $J$. Atmos. Sci., 39, 1290-1306.

- and D. Subramanian, 1982: The 30-50 day mode at $850 \mathrm{mb}$ during MONEX. J. Atmos. Sci., 39, 2088-2095.

Lau, N.-C. and M.J. Nath, 2000: Impact of ENSO on the Asian-Australian monsoons as simulated in GCM experiments. J. Climate, 13, 42874309.

Martin, G.M., 1999: The simulation of the Asian summer monsoon, and its sensitivity to horizontal resolution, in the UK Meteorological Office Unified Model. Quart. J. Roy. Meteor. Soc., 125, 1499-1525.

May, W., 1999: A time-slice experiment with the ECHAM4 A-GCM at high resolution: The experimental design and the assessment of climate change as compared to a greenhouse gas experiment with ECHAM4/OPYC at low resolution. DMI Scientific Report, 99-2, 93 pp.

, 2001: The impact of horizontal resolution on the simulation of seasonal climate in the Atlantic/European area for present and future times. Clim. Res., 16, 203-223.

- 2002: Simulated changes of the Indian summer monsoon under enhanced greenhouse gas conditions in a global time-slice experiment. Geophys. Res. Lett., 29, 10.0129/ 2001GL013808.

and E. Roeckner, 2001: A time-slice experiment with the ECHAM4 AGCM at high resolution: the impact of horizontal resolution on annual mean climate change. Clim. Dyn., 17, 407-420.

Oberhuber, J.M., 1993: Simulation of the Atlantic circulation with a coupled sea-ice-mixed layer-isopycnal general circulation model. Part I: Model description. J. Phys. Oceanogr., 22, 808-829.
Rasmusson, E.M. and T.H. Carpenter, 1983: The relationship between eastern tropical Pacific sea surface temperatures and rainfall over India and Sri Lanka. Mon. Wea. Rev., 111, 517-528.

Reynolds, R.W., 1988: A real time global sea surface temperature analysis. J. Climate, 1, 75-86.

Rodwell, M.J. and B.J. Hoskins, 1996: Monsoons and the dynamics of deserts. Quart. J. Roy. Meteor. Soc., 122, 2597-2611.

Roeckner, E., K. Arpe, L. Bengtsson, M. Christoph, M. Claussen, L. Dümenil, M. Esch, M. Giorgetta, U. Schlese and U. Schulzweida, 1996a: The atmospheric general circulation model ECHAM-4: Model description and simulation of present-day climate. MPI-Report, 218, $90 \mathrm{pp}$.

, L. Bengtsson, J. Feichter, J. Lelieveld and H. Rodhe, 1999: Transient climate change simulations with a coupled atmosphere-ocean GCM including the tropospheric sulfur cycle. J. Climate, 12, 3004-3032.

Roeckner, E., J.M. Oberhuber, A. Bacher, M. Christoph and I. Kirchner, 1996b: ENSO variability and atmospheric response in a global coupled atmosphere-ocean GCM. Clim. Dyn., 12, 737754.

Rudolf, B., 1993: Management and analysis of precipitation data on a routine basis. Proc. Int. WMO/IAHS/ETH Symp. on Precipitation and Evaporation, Bratislava, Slovakia, Slovak. Hydromet. Inst., 69-76.

Sankar-Rao, M., M.K. Lau and S. Yang, 1996: On the relationship between Eurasian snow cover and the Asian summer monsoon. Int. J. Climatol., 16, 605-616.

Sikka, D.R. and S. Gadgil, 1980: On the maximum cloud zone and the ITCZ over Indian longitudes during the southwest monsoon. Mon. Wea. Rev., 108, 1840-1853.

Sperber, K.R., J.M. Slingo and H. Annamalai, 2000: Predictability and the relationship between subseasonal and interannual variability during the Asian summer monsoon. Quart. J. Roy. Meteor. Soc., 126, 2545-2574.

Stendel, M. and K. Arpe, 1997: Evaluation of the hydrological cycle in reanalyses and observations. ECMWF Re-analysis Project Report Series, 6, $62 \mathrm{pp}$.

and E. Roeckner, 1998: Impacts of horizontal resolution on simulated climate statistics in ECHAM4. MPI-Report, 253, 57 pp.

Stephenson, D.B., F. Chauvin and J.-F. Royer, 1998: Simulation of the Asian summer monsoon and its dependence on model horizontal resolution. J. Meteor. Soc. Japan, 76, 237-265.

, K. Rupa Kumar, F.J. Doblas-Reyes, J.-F. 
Royer and F. Chauvin, 1999: Extreme daily rainfall events and their impact on ensemble forecasts of the Indian monsoon. Mon. Wea. Rev., 127, 1954-1966.

Stratton, R.A., 1999: A high resolution AMIP integration using the Hadley Centre model HadAM2b. Clim. Dyn., 15, 9-28.

Susskind, J., P. Piraino, L. Rokke, L. Iredell and A. Metha, 1997: Characteristics of the TOVS Pathfinder Path A dataset. Bull. Amer. Meteor. Soc., 78, 1449-1472.

Webster, P.J., 1983: The large-scale structure of the tropical atmosphere. In B. Hoskins and D. Pearce (eds.): Large Scale Dynamical Processes in the Atmosphere. Academic Press, San Diego, 235-276.

, V.O. Magaña, T.N. Palmer, J. Shukla, R.A. Tomas, M. Yanai and T. Yasunari, 1998: Monsoons: processes, predictability and prospects for prediction. J. Geophys. Res., 103, 1445114510.

and S. Yang, 1992: Monsoon and ENSO: selectively interactive systems. Quart. J. Roy. Meteor. Soc., 118, 877-926.

Xie, P. and P.A. Arkin, 1996: Analysis of global monthly precipitation using gauge observations, satellite estimates, and numerical model predictions. J. Climate, 9, 840-858. 